\title{
La importancia del concepto de permisión en los sistemas normativos y en el marco de los estados constitucionales $\left.{ }^{(*)}\right)^{(*)}$
}

\author{
The importance of the concept of permission in the normative systems and \\ the framework of constitutional states
}

\author{
Lily Ku Yanasupo(**) \\ Universidad de Génova (Génova, Italia)
}

\begin{abstract}
Resumen: La presente investigación analiza la importancia del concepto de permisión en los sistemas normativos a partir de la idea de que este no solo significa ausencia de prohibición, y que no basta con las nociones de prohibición/obligación para explicar dichos sistemas. En ese sentido, tomando como principal referente la teoría clásica de Carlos E. Alchourron y Eugenio Bulygin sobre los significados del término deóntico "permitido" según su uso prescriptivo y descriptivo, así como la distinción entre el ámbito de los sistemas normativos y el ámbito del razonamiento jurídico, la autora plantea que si bien una "conducta no prohibida" puede interpretarse como una "conducta permitida", esta interpretación no es suficiente para considerar que dicha conducta se encuentra regulada y disponible para el sujeto. En cuanto al análisis práctico de las normas permisivas, principalmente en el marco de los estados constitucionales, la autora explica la utilidad de estas para clausurar los sistemas jurídicos, generar la obligación de facilitar (o la prohibición de no interferir en) la acción referida en el permiso, y delimitar las competencias normativas cuando existen autoridades jerárquicamente ordenadas.
\end{abstract}

Palabras clave: Teoría Constitucional - Teoría del Derecho - Teoría de las normas Imperativismo - Sistemas normativos - Permisión - Normas permisivas

\begin{abstract}
This research analyzes the importance of the concept of permission in normative systems based on the idea that it does not only mean absence of prohibition, and that the notions of prohibition / obligation are not enough to explain these systems. In this sense, taking as main referent the classical theory of Carlos E. Alchourron and Eugenio Bulygin on the meanings of the deontic term "permitted" according to its prescriptive and descriptive use, as well as the distinction between the field of the normative systems and the field of legal reasoning, the author suggests that although a "non-prohibited conduct" can be interpreted as an "permitted conduct", this interpretation is not sufficient to consider that such conduct is regulated and available to the subject. Regarding the practical analysis of permissive rules, mainly in the framework of constitutional states, the author explains the utility of these to close the legal systems, generate the obligation to facilitate or the prohibition of not interfering in the action referred in the permit, and delimit the normative powers when there are hierarchically ordered authorities.
\end{abstract}

$\left(^{*}\right) \quad$ Nota del Editor: este artículo fue recibido el 24 de febrero de 2020 y su publicación fue aprobada el 17 de mayo de 2020.

$\left({ }^{* *}\right)$ Esta investigación está basada en el trabajo académico presentado por la autora para optar el grado de Máster en Estado de Derecho Global y Democracia Constitucional de la Universidad de Génova - Italia, en noviembre de 2017.

$\left({ }^{* * *}\right)$ Abogada por la Universidad Nacional Mayor de San Marcos, Magíster en Derecho Constitucional por la Pontificia Universidad Católica del Perú, Máster en Estado de Derecho Global y Democracia Constitucional por la Universidad de Génova (Italia) y Diploma en Justicia Constitucional y Derechos Humanos por la Universidad de Alcalá de Henares (España). Correo: likuya@gmail.com, Iku@ pucp.pe 
La importancia del concepto de permisión en los sistemas normativos y en el marco de los estados constitucionales

The importance of the concept of permission in the normative systems and the framework of constitutional states

Keywords: Constitutional Theory - Law theory - Rules theory Imperativism - Normative systems - Permission - Permissive rules

\section{Introducción}

El problema ontológico de las normas es un tema clásico en los estudios de teoría del derecho y filosofía moral que guarda relación con las teorías existentes sobre las concepciones de las normas, las cuales permiten determinar los tipos de intervención que la autoridad efectúa en la conducta humana ${ }^{(1)}$. Una de las más extendidas es la denominada teoría imperativista, que se basa en la idea de que el legislador se expresa generalmente de modo imperativo a través de las normas, es decir, para establecer obligaciones y prohibiciones. Característico de esta teoría es que, a la hora de reconstruir el sistema normativo, considera prescindible el concepto de permisión.

Sin embargo, en oposición a la teoría imperativista de las normas, existen estudios que señalan la importancia del concepto de permisión, definido no solo como ausencia de prohibición, sino como aquella conducta permitida por una norma. Los estudios que destacan la autonomía y relevancia de las normas permisivas se han desarrollado, sobre todo, a partir de la teoría clásica de Carlos E. Alchourron y Eugenio Bulygin (en adelante me referiré a estos autores como A\&B), recogida en su famoso libro Normative Systems. En este libro, y en trabajos posteriores de dichos autores, se plantean los diferentes significados del término deóntico "permitido" según su uso prescriptivo o descriptivo, así como la importancia de las normas permisivas para clausurar los sistemas jurídicos y delimitar las competencias normativas cuando existen autoridades jerárquicamente ordenadas.

Dichos enfoques teóricos con relación a las normas nos permiten tener dos planteamientos básicos sobre las normas permisivas. En el primero, subyace una teoría filosófica e interpretativa sobre la existencia de los sistemas normativos, que considera que el universo de las conductas se encuentra regulado por un permiso general que tienen los individuos para actuar libremente. Esta condición general de libertad atribuida a los individuos goza de un contenido jurídico que hace irrelevante la existencia de normas permisivas, y más bien cualquier excepción a este principio deberá estar regulado por normas de prohibición u obligación. Desde la lógica deóntica ${ }^{(2)}$, esto se puede expresar a través del principio de permisión según el cual tanto " $x$ " como la negación de " $x$ " están permitidos, de lo cual se deriva que (i) todas las conductas están reguladas por el derecho, aun cuando no estén contenidas en una norma expresa; y, (ii) el sistema normativo es cerrado y carente de lagunas, puesto que todas las conductas pueden ser deónticamente caracterizadas por dicho sistema.

En el segundo, parte del universo de las conductas se encuentra regido por un sistema normativo que regula a través de las normas. En el caso de las conductas no reguladas, se postula que no todas estas se consideran conductas permitidas en sentido débil, es decir, conductas con propiedades relevantes que se pueden ejercer con la simple aplicación de un principio general de libertad, sino que dentro de este grupo además hay conductas jurídicamente irrelevantes y conductas para cuyo ejercicio no es suficiente la presunción de que "están permitidas porque no están prohibidas", siendo necesario que antes se prevea normativamente un determinado estado de cosas.

Como puede verse, en ambos planteamientos se presenta la interrogante de si es necesario llevar a cabo una diferenciación entre el ámbito de los sistemas normativos (lo regulado y no regulado) y el ámbito del razonamiento jurídico (la calificación de las conductas), para determinar la importancia de las permisiones. Es decir, es cierto que una conducta no prohibida puede interpretarse como una conducta permitida, pero ¿esto es lo mismo a decir que "la conducta no

(1) Jordi Ferrer y Jorge L. Rodríguez (2011, p. 35) distinguen, por ejemplo, cuatro concepciones de las normas: sintáctica (las normas son enunciados), semántica (las normas son significados), mixta sintáctico-semántica (las normas son enunciados interpretados) y pragmática (las normas son el resultado del uso prescriptivo del lenguaje).

(2) La lógica deóntica (o lógica normativa) es la lógica formal de las normas y del razonamiento normativo. Esta lógica estudia las inferencias basadas en las relaciones lógicas entre los conceptos normativos que tienen como base la conducta humana, tales como "obligación", "prohibición", "permisión", etc. La lógica deóntica no reemplaza a la lógica proposicional, sino que la incluye. El estudio sistemático de este tipo de lógica comienza en 1951, a partir de la publicación del famoso artículo de Georg Henrik von Wright, titulado Deontic Logic (ideas tomadas del prólogo escrito por A\&B al libro Lógica, proposición y norma de los autores Echave, Urquijo y Guibourg, 1986, p. 11). 
prohibida es una conducta regulada y perteneciente al sistema normativo"?; en todo caso, ¿cuáles serían las razones jurídicas para que algunas conductas no prohibidas estén reguladas como permitidas?

En ese sentido, los objetivos de mi investigación serán determinar cuál de las posturas teóricas señaladas representa mejor la estructura y el funcionamiento de los sistemas normativos, principalmente en el marco de los estados constitucionales; si basta con las nociones de prohibición/ obligación para dar cuenta de dichos sistemas; y si el concepto de permisión es fundamental en dicha construcción. Para esto, será necesario distinguir entre las diferentes variantes de conductas permitidas.

Por último, este trabajo se propone servir para aportar, a través de un lenguaje simple y no esotérico, argumentos en contra de la tesis de la completitud y coherencia de los sistemas normativos, según la cual no existen lagunas ni conflictos; pues, aceptar una tesis como esta, nos puede llevar a cometer el gran error de ignorar que el derecho es un concepto social y dinámico, así como desconocer los criterios de validez o pertenencia de las normas.

\section{Sistema Normativo y Razonamiento Jurídico}

\subsection{Conductas reguladas y no reguladas}

Cómo regulan los sistemas normativos es un asunto crucial para definir la completitud del derecho o la posibilidad de que existan lagunas normativas. Si partimos de la idea general de que para garantizar ciertos fines jurídicos el legislador puede regular las conductas a través de la expedición de normas, que es posible extender el alcance de estas normas a través de ciertos mecanismos de interpretación, y que, además, los criterios de pertenencia y de razonamiento permiten por igual identificar los sistemas normativos, entonces podremos tener una conclusión preliminar de cuán completo es el derecho: diremos que lo abarca todo. Pero la práctica de los sistemas jurídicos demuestra que no todos los casos tienen propiedades jurídicamente relevantes o cuentan con una solución en términos normativos, y que no debemos confundir la aplicación de la lógica a las normas, con la validez de las normas.

Si bien el carácter ontológico de las conductas reguladas, aquellas contenidas en normas válidamente aprobadas por la autoridad competente y que, por ende, pertenecen al sistema normativo, nos permite suponer que previamente el legislador ha valorado las razones para determinar las propiedades relevantes que configuran dichas conductas, y así establecer una respuesta o solución, esto no debería llevarnos a pensar que todo aquello que no está regulado por norma es irrelevante jurídicamente, que todas estas conductas son indiferentes para el derecho o que de por sí constituyen lagunas normativas.

De conformidad con A\&B (1987, p. 146), la noción de relevancia es importante por cuanto proporciona un criterio de adecuación para la elección del universo de casos, en el sentido que: para todo sistema normativo existe un universo de propiedades relevantes, y es a partir de dicho universo de propiedades relevantes que se construye el universo de casos. Al respecto, Pablo Navarro (2007, p. 18) señala que: "la regulación de la conducta mediante normas generales exige, básicamente, la selección de un conjunto finito de circunstancias relevantes".

Las propiedades relevantes son aquellas que elige el legislador y designa como tal para configurar una conducta. El proceso de determinación de las propiedades relevantes, es decir, de las propiedades que merecen ser tenidas en cuenta para regular una conducta, es un problema subjetivo, valorativo o axiológico que atañe exclusivamente al legislador ${ }^{(3)}$. Una vez que se han determinado los casos posibles, las conductas a que estos se refieren se regularán a través de normas, pudiendo ser prescritas como obligatorias, prohibidas o permitidas.

Cabe señalar que la tarea legislativa consiste en una labor dinámica, en un proceso que conlleva una amplia ponderación de intereses; siendo así, la existencia de conductas reguladas no determina la irrelevancia prescriptiva de las propiedades

(3) La interrogante de cuándo y por qué una propiedad de un caso debe ser jurídicamente relevante, o qué o quiénes contribuyen a la determinación de estas propiedades, puede responderse apelando al balance entre principios o a fórmulas interpretativas, pero ciertamente nos referimos a una propiedad que debe ser relevante de acuerdo con un determinado criterio axiológico, el cual puede ser aportado por los jueces a través de sus sentencias, por la doctrina jurídica o cualquiera que argumente en derecho. Sin embargo, que estos criterios interpretativos sirvan para regular una conducta (caso y solución), dependerá de lo que finalmente el legislador -que tiene la tarea democrática de innovar el ordenamiento jurídico- considere como propiedades relevantes de dicha conducta, y es a eso a lo que trato de apuntar en este apartado. 
de las conductas no reguladas o, en todo caso, únicamente la irrelevancia descriptiva de estas propiedades, en tanto muchas de estas conductas no han sido sometidas a la valoración del legislador (o no pudieron ser consideradas ex ante o aún no se habían configurado) ${ }^{(4)}$.

Desde el enfoque de la lógica deóntica se plantea que las formas de regulación más usadas para prescribir las conductas a través de normas, por ende, las más analizadas son "permitido", "obligatorio", "prohibido" y "facultativo", aunque no exista un acuerdo respecto a si el operador deóntico "permitido" es autónomo, dado que este puede ser definido en términos de prohibición (Opalek \& Wolenski(5), 1973, p. 169; A\&B, 1987, p. 73).

De esta manera, se dice que todo acto o estado de cosas está regulado o deónticamente caracterizado en el sistema normativo como permitido o prohibido, haciendo que este sea cerrado y carente de lagunas, tal como consideraba von Wright; no obstante, otras posiciones plantean que existen casos que muestran que no puede mantenerse como principio general aplicable a todo el ordenamiento jurídico el principio de permisión o "lo no prohibido está permitido" (Iturralde, 1998, p. 189).

Rafael Rojina Villegas (1942, p. 31-32) consideraba que el llamado sector de los actos permitidos que no son regulados por el derecho, debido a la aplicación del principio "lo que no está prohibido está permitido", no es un sector de la conducta jurídica, sino que son actos que no están jurídicamente regulados porque aquí no existen interferencias intersubjetivas que conlleven facultades y deberes: "Se trata de un espacio vacío para el derecho que correctamente debe designarse como el sector de lo ajurídico".

Dice este autor, además, que la doctrina tradicional ha querido darle un contenido jurídico a dicho sector al considerársele como parte del ejercicio del derecho de libertad; sin embargo, considera que este tratamiento es equivocado: “(...) sería desorbitar el ámbito del derecho y desnaturalizar su objeto específico, si declarásemos que hacer lo que el derecho no prohíbe o dejar de hacer lo que no manda constituyen formas de conductas reguladas jurídicamente" (Rojina, 1942, p. 33).

Otros dos conceptos importantes para poder comprender mejor las formas en las que el derecho regula las conductas son los de sistema normativo y norma. Cabe señalar que en este punto se presentan algunas confusiones, porque se suelen adoptar al mismo tiempo criterios positivistas e interpretativos para definir el derecho y el sistema normativo. Esto en parte muestra que la regulación de las conductas es en realidad una tarea compleja.

Por lo general, el derecho suele observarse en un sentido abstracto o conceptual como un conjunto de normas con carácter prescriptivo coherentemente relacionadas, lo que hace que se le considere un sistema; sin embargo, el sistema normativo no representa en su totalidad el derecho, sino el conjunto de enunciados que conectan casos con soluciones ${ }^{(6)}$.

A\&B (1987, p. 95) plantean como concepto general que el sistema normativo consiste en un conjunto de enunciados que tiene (algunas) consecuencias normativas (para algún universo de casos y algún universo de soluciones), cuya función es establecer correlaciones entre casos y soluciones: "Un conjunto normativo es un conjunto de enunciados tales que entre sus consecuencias hay enunciados que correlacionan casos con soluciones. Todo conjunto normativo que contiene todas sus consecuencias es, pues, un sistema normativo". Para este concepto de sistema

(4) Utilizo aquí los conceptos de relevancia prescriptiva y descriptiva introducidas por A\&B (1987, p. 154-158), debido a que me permiten distinguir adecuadamente entre conductas reguladas y no reguladas. Al respecto, estos autores señalan que, para un caso, y en relación a un sistema normativo y un universo de soluciones, una propiedad es relevante en el sentido descriptivo cuando se afirma un estado de cosas que de hecho se da; en cambio, una propiedad es relevante en el sentido prescriptivo cuando se afirma que un estado de cosas debe o debería darse. Para graficar esta situación, por ejemplo, diremos que las lagunas axiológicas suponen la existencia de una propiedad relevante en sentido prescriptivo para el caso en cuestión, aunque esta propiedad sea irrelevante en el sentido descriptivo para el sistema considerado.

(5) En adelante me referiré a estos autores como O\&W.

(6) No obstante, para Jorge J. Rodríguez (2006, p. 260), bajo una concepción dinámica e institucional de los sistemas jurídicos, el derecho también puede ser entendido como un macrosistema, y el conjunto de las normas que un juez toma en consideración para resolver un problema puede reconstruirse como un microsistema. Este autor señala que estos microsistemas pueden estar conformados por normas vigentes en distintos espacios temporales del orden jurídico, o por normas que ya no integran ningún sistema de la secuencia que conforma el derecho vigente; lo cual demostraría la importancia de distinguir entre las nociones de "pertenencia" y "aplicabilidad" a la hora de reconstruir el sistema normativo e identificar las normas relevantes para la solución de un determinado caso (piénsese, por ejemplo, en la aplicación ultractiva de normas derogadas en materia penal o tributaria). 
normativo el énfasis estaría en las consecuencias normativas de sus enunciados ${ }^{(7)}$.

En cuanto al concepto de norma, A\&B (1987, p. 14) plantean un tratamiento sintáctico al considerar que las normas son entidades o expresiones lingüísticas que correlacionan casos con soluciones, sin que por ello se afecte el carácter ontológico de las mismas. Es decir, para dichos autores la producción de las normas consiste en un acto pragmático, cuyo resultado tiene un lado sintáctico y otro semántico ${ }^{(8)}$. Asimismo, Pablo Navarro (2007, p. 18) señala que: "Las normas jurídicas correlacionan ciertas circunstancias (casos) relevantes con calificaciones normativas (soluciones) de un conjunto de acciones. Esta correlación entre casos y soluciones determina las posiciones normativas, i.e. derechos y obligaciones de los individuos de una determinada comunidad".

En cambio, Riccardo Guastini (2017) sigue un esquema que busca demostrar que las concepciones semántica y pragmática de las normas son complementarias, en tanto entiende que el problema ontológico de las normas encierra dos cuestiones: el de su génesis y el de su naturaleza. La posición que finalmente adopta este autor es ecléctica: las normas son significados que solo adquieren existencia por medio de actos de lenguaje.

En cuanto a la naturaleza del resultado del proceso de producción de normas, Guastini señala que estas son los significados de enunciados usados para prescribir entidades abstractas similares a una proposición, en el sentido que ambas no deben ser confundidas con el enunciado que la expresa. Por tanto, una norma sería el significado de un enunciado interpretado. Esta sería la concepción semántica sobre la naturaleza de las normas ${ }^{(9)}$.

En relación con la génesis de las normas, Guastini refiere que es necesario tener presente los procedimientos para la producción jurídica, o los criterios de validez o pertenencia al sistema normativo. Sobre esto, Cristina Redondo (2006, p. 296) enfatiza que: "(...) si el derecho es entendido como conjunto de textos jurídicos, los criterios de validez son aquellos que indican las propiedades o relaciones que un texto debe satisfacer para poder afirmar que expresa o contiene una norma jurídica. Un texto que satisface la propiedad o relación en cuestión es, por esa razón, una fuente que expresa derecho".
Según Guastini (2017, p. 4-5), es una convicción positivista que "no existen normas -morales o jurídicas- sin actos de producción de normas", con lo cual "la existencia de cualquier norma depende, en última instancia, de un acto de producción normativa". Por ello, el pensamiento jurídico moderno (el de orientación iuspositivista, al menos) supone una concepción pragmática de la génesis de las normas ${ }^{(10)}$.

Para dicho autor, la promulgación de una norma por el órgano competente para regular determinadas conductas, que se entienden relevantes desde el punto de vista jurídico, sería condición suficiente para que se considere que dicha norma "pertenece" al ordenamiento jurídico (Guastini, 2001, p. 60). Es decir, no cabe mayor discusión sobre la pertenencia de las normas al sistema jurídico, en tanto estas hayan sido aprobadas cumpliendo con las normas para la producción jurídica que establecen procedimientos mínimos y necesarios, como la aprobación por el órgano competente y la publicidad según mandato constitucional. Ahora bien, la pertenencia al sistema jurídico conlleva cuatro atributos para las normas: existencia formal, fuerza vinculante, eficacia fáctica y aplicabilidad. Otro tema de discusión es la validez sustantiva de las normas, que no será objeto de la presente investigación.

Conforme a lo expuesto, es posible afirmar que todas las conductas reguladas tienen propiedades relevantes en sentido descriptivo y que todas estas conductas pertenecen al sistema normativo; pero ¿sería correcto afirmar que las propiedades de todas las conductas no reguladas son irrelevantes en sentido prescriptivo para el derecho? Pienso que no, que la existencia de conductas no reguladas no debe atribuirse $a$

(7) Para efectos de la presente investigación, las menciones al concepto de "sistema normativo" estarán referidas a un conjunto de normas, esto es, a un conjunto de formulaciones normativas interpretadas, y no a un conjunto de disposiciones o enunciados normativos sin interpretar. En ese sentido, deberá entenderse, tal como precisa Eugenio Bulygin (2010, p. 292), que "el proceso de la determinación o identificación de esas normas ya se ha cumplido; antes de haber identificado esas normas no tiene sentido hablar de lagunas o contradicciones normativas".

(8) Agradezco a Alejandro Calzetta por hacerme algunas precisiones en lo referente a este tema durante el desarrollo de mi investigación.

(9) En cambio, conforme a Guastini $(2017$, p. 5), para la concepción pragmática o expresiva el contenido semántico de un acto de prescripción es una proposición, por lo que identifica normas con proposiciones.

(10) En cambio, conforme a lo señalado por Guastini (2017, p. 2), para la concepción semántica o hilética las normas existen independientemente de cualquier hecho empírico. 
priori a que todas estas carecen de propiedades relevantes para el derecho.

Asimismo, que una conducta no regulada tenga ciertas propiedades relevantes en sentido prescriptivo, no determina su pertenencia al sistema normativo; dicha falta de pertenencia tampoco cambiaría por el hecho de que tal conducta pueda resolverse con la sola aplicación de mecanismos de interpretación, como se da en el caso de los permisos débiles ${ }^{(11)}$. No obstante, la distinción entre conductas no reguladas en función a la relevancia prescriptiva de sus propiedades pone en cuestionamiento que las lagunas normativas sean simples conflictos de intereses no solucionados por el orden jurídico.

Al respecto, Ruiz Manero precisa lo siguiente: “(...) las lagunas son, en efecto, conflictos de intereses no resueltos por el sistema jurídico, pero no todos los conflictos de intereses no resueltos por el sistema jurídico constituyen lagunas" (2005, p. 124). Podría darse el caso de conductas no reguladas cuyas propiedades, o algunas de ellas, son jurídicamente relevantes, y que a través de fórmulas interpretativas es posible brindarles respuesta o solución; en estos casos, tales conductas pueden realizarse sin mayor dificultad apelando a un principio general de libertad. Hablamos por ejemplo de la facultad que tienen las personas para comprar un automóvil, ir a misa o participar si lo desean en una agrupación política ${ }^{(12)}$. Sin embargo, que dichas conductas se consideren permitidas por la vía de la interpretación, no quiere decir que por ello pertenezcan al sistema normativo.

En efecto, tal como refiere Cristina Redondo (2006, p.298-299), la distinción entre criterios de validez y criterios interpretativos no es bizantina, dado que una cosa es la tarea de hacer explícitos los múltiples significados de un texto normativo o aplicar técnicas de razonamiento para intentar ampliar o restringir un contenido conceptual; y otra cosa es identificar, mediante la aplicación de criterios de pertenencia, cuáles de esos contenidos pertenecen al sistema, pues estos últimos criterios son los que determinan la identidad y la estructura del mismo. En ese sentido, afirmar que cualquier norma relacionada a los textos jurídicos es sin más una norma del sistema, significa pasar por alto la diferencia entre texto y norma, o considerar que dicha norma para ser válida no requiere cumplir ninguna propiedad adicional a la de haber sido obtenida mediante algún razonamiento interpretativo ${ }^{(13)}$.

En esa misma línea, Pablo Navarro (2011, p. 130-131) señala que una norma necesaria no es una norma positiva, por lo que es preciso distinguir entre los criterios para identificar una norma jurídica y los criterios que se emplean en el razonamiento jurídico; aunque estos últimos sean indispensables para razonar de manera adecuada, ello no quiere decir que formen parte del sistema normativo. Una manera adecuada para saber qué normas forman parte del derecho, es determinar si estas pueden ser eliminadas del sistema por las autoridades competentes a través de actos normativos específicos, como la derogación.

\subsection{Indiferencia y laguna normativa}

Desde la lógica deóntica, la indiferencia se considera una cualificación natural de todo acto humano que es anterior a cualquier formulación normativa. En virtud de esta definición se sostiene que las conductas no

(11) Esto guardaría relación con lo señalado por Cristina Redondo (2006, p. 297), en el sentido que: “(...) no todos los contenidos susceptibles de asociarse a una fuente de derecho son, por esa razón, normas del sistema. Lo son solo aquellos que satisfacen los criterios de pertenencia. (...) Un contenido normativo, o bien satisface los criterios de validez y es una norma jurídica válida en el sistema, o bien no".

(12) Conforme a Ruiz Manero (2005, p. 123): "La definición de laguna normativa excluye de su ámbito aquellos casos no cubiertos por una regla, pero en relación con los cuales el balance de los principios relevantes del sistema determinaría que esta permitiese tanto la realización como la omisión de la conducta de que se trate". Precisa dicho autor en un trabajo posterior (Ruiz Manero, 2015, p. 50) que: "(...) Si no hay principios prima facie aplicables al caso de acuerdo con los cuales el caso sea relevante o sí, aun habiendo tales principios, su balance no exige una regla que lo correlacione con una solución normativa, el caso, sencillamente, no es un caso de laguna. El primer supuesto -que el caso no sea relevante desde el punto de vista de los principios- se produce en un caso como (...) la acción de ingerir zumo de naranja en el desayuno (...). El segundo supuesto, que aun teniendo el caso relevancia desde el punto de vista de los principios, no sea necesaria una regla que lo correlacione con una solución normativa. se produce en aquellos casos en los que, incontrovertiblemente, la eventual regla no podría ser más que permisiva".

(13) Concebir al derecho como un sistema deductivo (es decir, como un conjunto de significados expresados en determinados textos, el cual contiene todas sus consecuencias lógicas), no es una cuestión pacífica, pues en este modelo la deducibilidad o la aplicación de razonamientos lógicos válidos constituye un criterio de pertenencia al sistema normativo. Por ello, para Cristina Redondo (2006, p. 300-303) la deducibilidad -que es uno de los aspectos centrales de la caracterización del derecho por A\&B, pues se cree que capta la manera corriente como los juristas comprenden el derecho- no solo no se condice con la mayoría de las teorías jurídicas sino también con la práctica de los sistemas jurídicos, pues si bien los operadores del derecho aplican la lógica a las normas, de ello no se sigue que acepten que la deducibilidad sea un criterio de pertenencia al sistema. 
reguladas son actos indiferentes para el derecho debido a que es posible tanto ejercerlas como no, es decir, existe una doble libertad de hacer y no hacer, y esa posibilidad tiene la misma connotación que una conducta permitida. La indiferencia entendida como permisión es la expresión de la libertad metafísica del hombre ${ }^{(14)}$.

Conforme a lo anterior, se dice que el derecho permite determinadas conductas con el solo hecho de no prohibirlas normativamente, haciendo innecesaria la aprobación de normas que confieran esta doble libertad de hacer o no hacer. No obstante, para algunos autores, dentro de la lógica deóntica la indiferencia es una noción más estricta que la de permisión, pues lo indiferente siempre está permitido, pero no todo lo que está permitido es indiferente; por ejemplo, un acto que es obligatorio es un acto que también está permitido, pero en modo alguno podría considerarse un acto indiferente (Francisco Velásquez, 2015, p. 107). Esto demostraría las dificultades que existen a la hora de asimilar el discurso lógico con el discurso normativo.

El fundamento jurídico que se le atribuye a la indiferencia normativa es el derecho a la libertad de las personas, y esta es la idea que también subyace a la teoría del espacio jurídico vacío. A través de la indiferencia, como señala Victoria Iturralde (1998, p. 197-199), se interpreta que las conductas no reguladas se encuentran "negativamente reguladas por el orden jurídico", o reguladas como conductas que no están jurídicamente prohibidas, por ende, están permitidas. En un sentido parecido, Hans Kelsen (1998, p. 252) explicaba que: "(...) el orden jurídico no solo regula positivamente la conducta humana, al ordenar determinado comportamiento ( ) como obligatorio, sino también negativamente en tanto permite determinada conducta en tanto no la prohíbe. Lo que no está jurídicamente prohibido, está jurídicamente permitido".

De acuerdo con esta noción puramente estática del derecho, tendríamos que asumir que el derecho regula el universo de las conductas, que este universo es inalterable y que todas las conductas comprendidas en él tienen propiedades relevantes para el derecho; con lo cual el derecho sería un sistema cerrado (no existen casos no regulados) y completo (no existen lagunas normativas) ${ }^{(15)}$. Esta conclusión sería bastante cuestionable, es decir, que incluso las interpretaciones de aquellas conductas que no han sido reguladas a través de normas expresas, formarían parte del sistema normativo(16).

Por su parte, los autores O\&W (1973, p. 170) plantean que el concepto normativo de indiferencia puede reemplazar el concepto de permiso y la esfera extranormativa, en tanto la indiferencia es asimilable al permiso bilateral. En el permiso bilateral una conducta es indiferente si a través de una norma está permitida hacerla como no hacerla, por lo que respecto de esta conducta el sistema normativo es completo y coherente. Sin embargo, para A\&B (1991, p. 230) la propuesta de dichos autores resulta poco clara dado que el concepto de indiferencia que plantean incluye la existencia de una norma que permite hacer y no hacer una determinada

(14) Luc J. Wintgens señala que, en ausencia de cualquier limitación externa impuesta por el derecho, todo sujeto es libre de actuar como uno quiera. Asimismo, el sujeto encara una infinita variedad de posibilidades para concretar el concepto de libertad, el cual incluye cualquier acción (2003, p. 266). Esta definición corresponde con la libertad natural o metafísica del hombre, que se interpreta como un permiso general para actuar libremente. El principio general de libertad sigue siendo una pieza fundamental en la estructuración de los sistemas jurídicos, en el sentido que: "La libertad no necesita ser probada -se debe probar que hay una norma en vigor imponiendo un deber de hacer o no hacer algo-" (Iturralde 1998: 198). Sobre la cláusula general de libertad en Alemania, cfr., por ejemplo, Robert Alexy, Teoría de los derechos fundamentales, Centro de Estudios Constitucionales, Madrid, 1993, p. 331-380. En parte, el cuestionamiento que planteo con la presente investigación, tal como lo hiciese A\&B (1991, p. 239), es si esta libertad originaria es equivalente a la libertad normativa que nace de un acto de autoridad.

(15) Al respecto, Juan Carlos Bayón (2009, p. 30) considera que Bulygin al pretender rebatir la idea de que todo derecho es un sistema completo, dado que para Bayón, por razones lógicas, no pueden haber situaciones no reguladas por el derecho y, por ende, lagunas normativas, comete el error de tratar como intercambiables las ideas de "ausencia de lagunas" (que permitiría afirmar que el sistema es "completo") y "ausencia de situaciones no reguladas" (que permitiría afirmar que el sistema es "cerrado"). Para graficar esta confusión, Bayón cita la alusión que hace Bulygin (1987, p. 172) de sistema cerrado como "carente de lagunas". Sin embargo, si partimos de la idea, como hace Bayón, de que no puede haber situaciones no reguladas por el derecho, estaríamos diciendo que: (i) todas las situaciones tienen propiedades relevantes y por eso todas están reguladas, o (ii) el sistema normativo regula todas las situaciones sin importar si estas tienen propiedades relevantes. Se puede inferir que en ambos supuestos dicho sistema carece de lagunas normativas, pues en cualquier caso las situaciones que tienen propiedades relevantes estarían reguladas, con lo cual es posible afirmar que un sistema cerrado implica que este carezca de lagunas normativas, como hizo Bulygin.

(16) Creer que este tipo de planteamiento puede resolver el problema de la completitud normativa es erróneo, pues la completitud se analiza en relación a un determinado sistema normativo: "(...) el supuesto hecho de que las conductas humanas tengan un carácter normativo basado en su estructura ontológica, es irrelevante para el problema de la completitud" (A\&B, 1987, p. 215). 
conducta, es decir, se refieren a conductas reguladas; por lo tanto, ¿cómo la indiferencia, que se refiere a conductas reguladas, podría asimilarse a la esfera extranormativa, cuando esta trata sobre el conjunto de las conductas no reguladas?

Si partimos del concepto de indiferencia que brindan $\mathrm{O} \& \mathrm{~W}$, tendríamos que decir que las conductas no reguladas no son conductas indiferentes, sino conductas no prohibidas o permisos débiles, pero, como sabemos, estas pertenecen al ámbito de las proposiciones normativas y no de las normas ${ }^{(17)}$, por lo que, en relación a estas, el sistema normativo es incompleto. Recordemos que un sistema normativo es completo cuando no existe ningún caso (relevante) al cual no esté correlacionada alguna solución(18).

Ahora bien, que la realización o no de una determinada conducta sea indiferente para el derecho, desde mi punto de vista, nos debería decir algo respecto a la relevancia de sus propiedades, con lo cual, contrario a lo que plantean O\&W, considero que la indiferencia sí guardaría relación con las conductas no reguladas y con la esfera extranormativa, aunque no en un sentido de equivalencia. El concepto de indiferencia presupone la irrelevancia jurídica de las propiedades de las conductas indiferentes, mas no de todas las conductas no reguladas ${ }^{(19)}$. Por ello, en la práctica de los sistemas jurídicos es posible distinguir el concepto de indiferencia -que, conforme a lo señalado, se refiere a conductas con propiedades jurídicamente irrelevantes y que se encuentran "más allá de las fronteras del derecho" (Ruiz Manero, 2005, p. 105)- de aquellas conductas no reguladas que tienen propiedades relevantes, situaciones en las que se configuraría lo que conocemos como lagunas normativas (casos para los que no existe una solución, la cual se considera necesaria).

En ese sentido, a partir del concepto de indiferencia normativa que he tratado de establecer, podríamos plantear la siguiente idea: las lagunas son casos no regulados, pero no todos los casos no regulados son lagunas; en efecto, no se trata de aquellos casos en los que el derecho no regula ni pretende regular (por el momento) ${ }^{(20)}$, sino de aquellos casos para los que el derecho no contempla solución normativa alguna, a pesar que tienen propiedades jurídicamente relevantes (Bulygin, 2005, p. 39).

Para A\&B (1987, p. 189, 214), cuando una determinada conducta no está normada por un determinado sistema normativo, generando que de dicho sistema normativo no sea posible inferir ninguna solución para el caso en cuestión, entonces este caso se configura en una laguna normativa, haciendo que el sistema sea incompleto en relación con un cierto universo de casos y un cierto universo de soluciones. Un sistema que no tiene lagunas es completo; en cambio, un sistema normativo es incompleto si, y solo si, tiene por lo menos una laguna. Por lo tanto, estos autores dirán que las lagunas son una propiedad de un determinado sistema normativo en relación con un conjunto de

(17) Conforme a Bulygin (2009, p. 9-10): “(...) las normas son usadas prescriptivamente para ordenar, prohibir o permitir una determinada conducta (en ciertas circunstancias) y como tales carecen de valores de verdad: no son ni verdaderas ni falsas. Las proposiciones normativas son afirmaciones acerca de (la existencia de) las normas; son descriptivas y, por ende, verdaderas o falsas". Asimismo, "(...) las normas pueden ser obedecidas o no, pueden ser calificadas como justas, válidas o eficaces, pero no son ni verdaderas ni falsas, mientras que las proposiciones normativas son verdaderas o falsas, pero no prescriben nada y en consecuencia no son ni válidas ni inválidas y no pueden ser obedecidas ni violadas".

(18) La idea de completitud requiere que todos los casos (que tienen propiedades relevantes para el derecho) tengan una solución (A\&B, 1987, p. 35-44). Al respecto, para Cristina Redondo (2006, p. 304), no se debe confundir un ideal racional de completitud, que debe entenderse como aquello que el sistema normativo puede satisfacer de manera contingente (brindar una solución normativa para todos los casos con propiedades relevantes), con la ilusión racionalista de que el derecho ofrece una solución para todos los casos posibles, algo que es lógicamente imposible.

(19) Pablo Navarro (2011, p. 137) grafica esta situación de la siguiente manera: "Para poder identificar si, por ejemplo, rascarse la oreja cuando es feriado es algo más que un caso sin solución (i.e., un caso de laguna), hay que identificar previamente a las normas que se refieren a esa acción y, luego, analizar si esas normas señalan a los días feriados o laborales como propiedades relevantes para imponer una cierta solución. Si ninguna norma conecta a esa propiedad con esa acción, entonces el caso es irrelevante (...). Si ninguna norma se refiere a esa acción de rascarse la oreja, entonces la propiedad de ser feriado o laborable carece completamente de interés".

(20) La relevancia (o irrelevancia) de las propiedades de ciertas conductas no parece ser una cuestión estática, sino más bien un concepto dinámico, pues esta calificación puede variar en función a diversos factores que deberán ser tomados en cuenta por el legislador. Por ejemplo, seguramente que hace cien años a nadie se le hubiese ocurrido plantear como una propiedad relevante del matrimonio, la unión sentimental de personas del mismo género; no obstante, en la actualidad muchos sistemas normativos consideran importante contemplar una regulación para tales conductas, debido a su vinculación con la concretización de derechos como la igualdad e identidad, y a la importancia de amparar las obligaciones, deberes y derechos que estas relaciones conllevan. 
circunstancias (casos) y un conjunto de conductas calificadas deónticamente (soluciones).

Respecto al tema de las lagunas normativas, las respuestas de los juristas han sido muy variadas. Kelsen (1998, p. 255), por ejemplo, explicaba que lo esencial de la teoría de las lagunas reside en señalar que la aplicación del derecho válido no es posible en un caso concreto cuando ninguna norma jurídica general se refiere a ese caso, lo cual para él hacía que dicha teoría sea errada, pues no tomaba en cuenta que cuando el orden jurídico no estatuye ninguna obligación a cargo de un individuo, su comportamiento está permitido: “(...) en el caso de que no sea posible la aplicación de una norma jurídica aislada, es posible en cambio la aplicación del orden jurídico, y ello también constituye la aplicación de derecho".

Por su parte, Juan Ruiz Manero (2015, p. 51) refiere que: "un cierto caso (genérico) constituye una laguna jurídica de un cierto sistema jurídico si y solo si 1) ese sistema jurídico no contiene una regla que correlacione el caso con una solución normativa y 2) el balance entre los principios de ese sistema jurídico prima facie aplicables al caso exige una regla que correlacione el caso con una solución normativa que califique la conducta de que se trate como obligatoria o prohibida". Respecto a la condición 2, este autor se refiere a que, aun teniendo propiedades relevantes el caso, no sería necesaria una regla específica que correlacione el mismo con una solución normativa, en tanto la eventual regla tuviese que ser permisiva, pues para cualquier efecto existe equivalencia pragmática entre la ausencia de regla y la regla permisiva.

Otros autores plantean la necesidad de eliminar las lagunas normativas regulando dichos casos, es decir, apelan a la introducción de nuevas normas a través de los mecanismos formales existentes; frente a esto, otros plantean la extensión del alcance de las normas existentes a través de ciertas prácticas interpretativas 0 interpretativocreativas ${ }^{(21)}$.

En cualquier caso, el concepto de laguna se vincula directamente con la idea de completitud del sistema normativo, cuya estructura, para A\&B (1987, p. 13), relaciona un conjunto de normas, un conjunto de situaciones fácticas o casos posibles y un conjunto de respuestas o soluciones posibles. Negar la existencia de lagunas normativas, o decir que todos los sistemas normativos son necesariamente completos, deriva en parte de la tesis que plantea la interdefinibilidad de "permitido" y "prohibido", la cual adolece de una falta de claridad para distinguir entre normas y proposiciones normativas, tal como explico en el siguiente capítulo.

En conclusión, y conforme a lo desarrollado en esta primera parte, considero que solo las conductas reguladas pertenecen al sistema normativo; en cambio, no pertenecen al sistema aquellas conductas no reguladas con propiedades relevantes que no tienen una respuesta o solución por parte del sistema (laguna normativa), o las que a través de la aplicación de prácticas interpretativas podrían tener una respuesta o solución (permiso

(21) Para Juan Carlos Bayón (2009, p. 61), los jueces pueden cambiar las soluciones formuladas por el legislador porque ellas solo imponen una calificación prima facie, con lo cual se podría decir que los legisladores a través de las normas solo brindan respuestas provisorias e incompletas, y que los jueces deben completar estas normas a través de ciertas prácticas interpretativas: “(...) el derecho puede ser contemplado como una estructura que consta de dos niveles, el de las reglas expresas y el de los principios o razones que constituyen las justificaciones subyacentes a las mismas (o, si se quiere, el de las calificaciones normativas expresas o prima facie y el de las concluyentes o definitivas)". Al respecto, las respuestas de Bulygin (2010, p. 292-293) y Navarro (2013, p. 114-115) a dicho planteamiento van en un sentido bastante parecido. El primero refiere que el tema del doble carácter del derecho y de los principios subyacentes está fuera de la discusión sobre la supuesta equivalencia pragmática entre permiso y no prohibición, salvo que uno crea que el balance entre los principios conduce necesariamente a sistemas cerrados, a la completitud de todos los sistemas posibles, o a un conjunto de normas que solucionen todos los casos posibles. Y con esto -aclara Bulygin- no se pretende negar la existencia de los principios o de las razones justificativas subyacentes a las formulaciones normativas del legislador (algo que equívocamente le atribuye Ruiz Manero), lo que se pretende precisar es que la introducción de principios no va más allá de ampliar la cantidad de normas (de un conjunto de normas formuladas expresamente a un conjunto más amplio formado por las calificaciones definitivas resultantes del balance entre los principios), pero nada dice que este nuevo conjunto será completo. EI segundo precisa, además, que del hecho de que existan prácticas interpretativas que atribuyen relevancia prima facie a las razones subyacentes, no se deriva que también existan prácticas que otorguen a ciertas normas (ya sean formuladas por las autoridades o impuestas por los intérpretes) un valor concluyente: “(...) la justificación para revisar las normas expresamente formuladas por las autoridades (e.g., la aparición de casos recalcitrantes) también presiona para la revisión de las relaciones de prioridad entre clases de casos que fijan las prácticas interpretativas. No tiene mucho sentido sostener que las decisiones expresas de las autoridades ofrecen calificaciones prima facie y sostener que las decisiones interpretativas (más o menos articuladas) en una cierta comunidad tienen fuerza concluyente para diferentes clases de casos. En otras palabras, otro tribunal podría resolver de manera diferente un caso similar y esto no es solo una cuestión de hecho sino de los poderes normativos que tienen los tribunales de revisar el derecho a la luz de las razones relevantes para la solución de un caso". 
La importancia del concepto de permisión en los sistemas normativos y en el marco de los estados constitucionales

The importance of the concept of permission in the normative systems and the framework of constitutional states

débil); tampoco pertenecen al sistema las conductas no reguladas cuyas propiedades son jurídicamente irrelevantes (indiferencia normativa). Esto se puede resumir a través del siguiente cuadro:

\begin{tabular}{|c|c|c|c|}
\hline \multicolumn{4}{|c|}{$\begin{array}{l}\text { CONDUCTAS REGULADAS Y NO REGULADAS, Y EL PRINCIPIO DE } \\
\text { PERMISIÓN }\end{array}$} \\
\hline \multirow{3}{*}{$\begin{array}{l}\text { Conductas } \\
\text { no } \\
\text { reguladas }\end{array}$} & \multirow{2}{*}{$\begin{array}{l}\text { Con relevancia } \\
\text { jurídica }\end{array}$} & $\begin{array}{l}\text { Conductas que se pueden } \\
\text { hacer o no hacer a través del } \\
\text { principio de permisión (vía } \\
\text { interpretación). }\end{array}$ & $\begin{array}{l}\text { No pertenecen al } \\
\text { sistema normativo, } \\
\text { pero constituyen } \\
\text { permisos débiles. }\end{array}$ \\
\hline & & $\begin{array}{l}\text { Conductas que no se pueden } \\
\text { hacer con la sola aplicación } \\
\text { del principio de permisión } \\
\text { (requieren de norma). }\end{array}$ & $\begin{array}{l}\text { No pertenecen al } \\
\text { sistema normativo, } \\
\text { por ende, } \\
\text { constituyen lagunas } \\
\text { normativas. }\end{array}$ \\
\hline & $\begin{array}{l}\text { Sin relevancia } \\
\text { jurídica }\end{array}$ & $\begin{array}{l}\text { Conductas que se pueden } \\
\text { hacer o no hacer, pero que le } \\
\text { son indiferentes al derecho. }\end{array}$ & $\begin{array}{l}\text { No pertenecen al } \\
\text { sistema normativo, } \\
\text { por tratarse } \\
\text { de conductas } \\
\text { indiferentes. } \\
\end{array}$ \\
\hline $\begin{array}{l}\text { Conductas } \\
\text { reguladas }\end{array}$ & $\begin{array}{l}\text { Con relevancia } \\
\text { jurídica }\end{array}$ & Tienen naturaleza normativa. & $\begin{array}{l}\text { Pertenecen al } \\
\text { sistema normativo }\end{array}$ \\
\hline
\end{tabular}

\section{La supuesta completitud y coherencia de los sistemas normativos}

\subsection{Algunas concepciones de las normas y la permisión}

Desde una noción clásica, las normas se dirigen a imponer un determinado comportamiento a los sujetos con el fin de mantener el orden, lo que les da la propiedad de ser obedecidas o incumplidas, eficaces o ineficaces; sin embargo, no es posible alcanzar esta finalidad con los permisos, los cuales: "(...) no desempeñan el rol de imponer un comportamiento, lo que hace surgir el problema (o el deseo) de desembarazarse de esta incómoda categoría conceptual, reduciéndola a normas imperativas (prohibiciones u obligaciones) o a normas de otro tipo (definiciones, normas abrogativas, etc.)" (Poggi, 2004, p. 12).

Para A\&B, el problema sobre la existencia de las normas permisivas está relacionado con el estatus ontológico y las propiedades lógicas de las normas, tal como identificaron en un trabajo que publicaron en 1981, denominado The Expressive Conception of Norms, el cual aborda dos concepciones respecto a la naturaleza de las normas: la concepción hilética que nos brinda una noción semántica de las normas, y la concepción expresiva que nos brinda una noción pragmática.

En la concepción hilética, las normas son independientes del lenguaje o no dependen de expresión lingüística alguna (aunque solo pueden ser expresadas por medio del lenguaje), por ello son entidades puramente abstractas o conceptuales. Desde esta postura se sostiene que el operador normativo (obligatorio, prohibido, permitido) forma parte del contenido conceptual de la norma, al igual que la proposición normativa (por ejemplo, "votar"): obligatorio votar $=\mathrm{Op}=\mathrm{p}$ debe ser hecho. Quienes comparten la concepción hilética aceptan por lo menos dos tipos de normas: las normas imperativas y las normas permisivas (A\&B, 1991, p. 122, 126).

En la concepción expresiva, las normas son el resultado del uso prescriptivo del lenguaje, expresiones o entidades pragmáticas que son esencialmente órdenes. Aquí -a diferencia de lo que sucede en la concepción hilética, los indicadores del tipo de acto lingüístico llevado a cabo (aseveración, interrogación, orden, etc.) no forman parte del contenido conceptual de la oración (por ejemplo, "José cocina") y solo muestran la forma en que esta es usada, es decir, no tienen relevancia semántica: “¡José, cocina!" es ordenado. A\&B (1991, p. 122-126, 146) señalan que la mayoría de los expresivistas rechazan la posibilidad de normas permisivas, lo que no implica negar la existencia de estados de cosas permitidos, y esto es así porque aceptan un solo tipo de acción normativa que sería la de ordenar. Esta versión de la concepción expresiva es la más popular y corresponde a la teoría imperativista de las normas (también denominada versión "reductiva" u "ockhamita")(22).

La teoría imperativista de la concepción expresiva de las normas reconoce cierta autonomía de los actos de habla que crean

(22) Cabe señalar, tal como precisan A\&B (1991, p. 133, 146, 148), que la concepción expresiva de las normas no se reduce al imperativismo, pues existe otra alternativa para dar cuenta de los actos que consisten en otorgar un permiso o una autorización, aunque esta sea aceptada por pocos expresivistas. Esta sería la versión "moritziana" que admite la posibilidad de que existan actos de habla diferentes a los de ordenar, tales como "permitir", así como la existencia de normas permisivas. A\&B precisan que esta versión propone representar las normas acto que crean permisos y facultades, por medio de la pertenencia de sus componentes descriptivos a un conjunto distinto del conjunto cuyos contenidos son productos de los "actos de ordenación", que sería el conjunto de acciones y estados de cosas permitidos. 
permisos, pero los reduce a los actos que levantan o derogan prohibiciones (actos de rechazo), los cuales no tienen la misma naturaleza que los actos de promulgación que crean obligaciones y prohibiciones. Asimismo, A\&B (1991, p. 137) precisan que esta versión pone los actos de rechazo en un conjunto separado del conjunto cuyos contenidos son productos de los "actos de ordenación", el cual estaría dado por los contenidos proposicionales que describen acciones y estados de cosas explícitamente rechazados, denominado el conjunto derogador, con la finalidad de proteger el sistema de las contradicciones que podrían generarse de la existencia de acciones o estados de cosas facultativos.

De manera que los imperativistas admiten un solo tipo de acto normativo: el de ordenar y, por ende, un solo tipo de normas: las imperativas (obligaciones y prohibiciones), por lo que el acto de ordenar puede ser descrito como el acto de promulgar una norma (A\&B, 1991, p. 127). Los actos de promulgación, como hechos empíricos, tienen que ver con el cumplimiento de los aspectos formales para determinar la existencia y pertenencia de las normas jurídicas al sistema normativo.

En ese sentido, para la teoría imperativista de la concepción expresiva de las normas no existen normas permisivas, pero sí proposiciones o estados de cosas permitidos, de forma que la permisión de una conducta está dada por la ausencia del acto de prohibir dicha conducta (permisión negativa) o por el acto de levantar o derogar la prohibición de dicha conducta (permisión positiva), en cambio, las obligaciones y prohibiciones requieren de ciertos actos normativos (A\&B, 1991, p.131, 146)

En general, una concepción reductiva, monista e imperativista de las normas sostiene que no existen normas permisivas, pues permitir no constituye (por definición) un uso normativo del lenguaje, es decir, que el concepto mismo de norma permisiva constituiría una contradicción en los términos, por ende, todas las normas de conducta se reducen a obligaciones o prohibiciones (Poggi, 2004, p. 12). También se señala que la línea de razonamiento del imperativismo postula el principio de prohibición como un presupuesto pragmático de la teoría normativa, y no como una "norma de clausura" contingente: "es lógicamente posible construir un sistema teórico sobre la base de las permisiones, pero los órdenes normativos reales (desde el derecho hasta el ajedrez) solo ofrecen utilidad cuando prohíben y porque prohíben" (Echave, Urquijo y Guibourg, 1986, p. 158).

Sin embargo, el imperativismo al que más se opondría mi trabajo sería a la versión fuerte o radical desarrollada por O\&W (1991, p. 342; 2014, p. 44), quienes proponen una tercera concepción de las normas denominada la concepción no lingüística, según la cual las normas son actos de hacer algo obligatorio o prohibido o decisiones expresadas en oraciones normativas: "(...) normar es una especie de acto, norma es el producto de ese acto, y enunciado normativo es la expresión de la norma. No es necesaria acá una caracterización más precisa del acto de normar. Será suficiente con decir que la norma es siempre una decisión". Conforme a esto, las normas no son enunciados o entidades lingüísticas, sino órdenes o decisiones que son establecidas, obedecidas y válidas.

Tal como precisa posteriormente Wolenski (2018, p. 6), "el objetivo y la función de la regulación normativa (brevemente: normación) es establecer cuales acciones son obligatorias, cuales prohibidas y cuales indiferentes; el ámbito de lo permitido es una conjunción de los ámbitos de lo obligatorio y lo indiferente".

Cabe señalar que, de acuerdo a dicha concepción, un sistema normativo es concebido como un conjunto de consecuencias lógicas de un determinado conjunto finito de obligaciones básicas, cuyos enunciados expresan una decisión de una autoridad normativa de que algunas acciones se consideran obligatorias, por lo que no hay espacio para los conceptos de permiso débil (negativo) o permiso fuerte (positivo) (O\&W, 1991, p. 337). En ese sentido, la teoría no lingüística de normas resultante "es una teoría no cognoscitivista, dado que cualquier decisión normativa es exterior al universo normado de acciones y los enunciados realizativos ${ }^{(23)}$ que expresan una normación no son descripciones del universo de acciones". Esta última concepción representa una dificultad a la hora de establecer las funciones que cumplen las normas permisivas y que hacen que sean relevantes para los sistemas normativos.

\subsection{El uso prescriptivo y descriptivo de los términos deónticos: los conceptos de permiso \\ Para A\&B, los conceptos de permiso suscitan} discusión en el ámbito de la lógica deóntica

(23) El enunciado realizativo, conforme al mencionado autor, es un enunciado indicativo. Por ejemplo: "establezco que A es obligatorio = OA", es decir, dicho enunciado expresa mi decisión normativa de que A es obligatorio. 
y en la filosofía del derecho, pues si bien estudios previos como los de von Wright se encargaron de distinguir entre permiso fuerte o positivo y permiso débil o negativo, este autor omitió establecer la distinción entre los conceptos deónticos prescriptivos y descriptivos, y entre el permiso descriptivo fuerte y débil, lo cual es fundamental para esclarecer la supuesta interdefinibilidad de los términos "permisión" y "prohibición", por lo cual se dice que todos los sistemas normativos son completos, y resolver el problema de las lagunas normativas.

Por lo general se piensa que no existen normas permisivas porque todas las normas son imperativas (prohíben u obligan), planteamiento básico de la teoría imperativista de las normas, de lo cual se deriva la "tesis refleja" que señala que la permisión no es más que la ausencia de prohibición. De esta tesis también se deriva la idea de la interdefinibilidad de los términos "prohibición" y "permisión", en el sentido que la permisión es la no prohibición, y la prohibición es la no permisión; o la regla permisiva de clausura, según la cual "lo que no está prohibido, está permitido": "La interdefinibilidad de los operadores deónticos solo significa que tanto las normas imperativas, que establecen prohibiciones y obligaciones, como las normas permisivas, que autorizan la realización o la omisión de una acción, pueden ser formuladas en términos de prohibición, obligación o permisión, indistintamente" (Bulygin, 2010, p. 287).

Conforme a lo anterior se podría concluir que lo no prohibido está permitido siempre, y lo no permitido deriva siempre en una conducta prohibida. Decir que todas las acciones o estados de cosas existentes están calificados como prohibidos o permitidos por el sistema normativo, supondría que todas esas acciones y estados de cosas se encuentran regulados por dicho sistema, con lo cual este sería completo y cerrado, no siendo posible hablar de lagunas normativas, conductas jurídicamente irrelevantes, y en general, de acciones o estados de cosas no regulados.

Una tesis como la anterior, que se basa en la ilusión de que los sistemas normativos contiene regulaciones para todas las acciones y estados de cosas en un determinado universo de casos, o que cuando el derecho no dice nada lo hace porque con su silencio quiere atribuir un carácter jurídico a las conductas no prohibidas o no reguladas, solo puede tener cabida como un ideal racional de completitud ${ }^{(24)}$. Pero, aceptar dicha tesis en todos los casos, nos llevaría a desconocer que el derecho es un concepto dinámico, así como desconocer los criterios de validez o pertenencia de las normas al sistema normativo.

En efecto, la práctica de los sistemas jurídicos muestra que no siempre es posible equiparar una conducta regulada como no prohibida (o permitida) con una conducta no prohibida (un término indefinido), y esto pasa por saber distinguir entre normas ${ }^{(25)} y$ proposiciones normativas, omisión que para Bulygin (2010, p. 284) es la raíz de todos los males a la hora de abordar el tema de las normas permisivas y los permisos.

Respecto a la supuesta completitud de los sistemas normativos, von Wright introdujo en 1959 la distinción entre permiso fuerte y permiso débil, según la cual en el "permiso débil" una conducta está permitida si no está prohibida (corresponde a la tesis refleja). En cambio, en el "permiso fuerte" una conducta está permitida: (i) si no está prohibida, pero además ha sido regulada a través de una norma; o, (ii) si la autoridad ha considerado su estatus normativo (está prohibida o está contenida en una obligación) y decide permitirla (A\&B, 1991, p. 217).

Las afirmaciones de (i) y (ii) no son equivalentes: en el primer caso se trata de una conducta que todavía no ha sido sometida a regulación; y en el segundo, hablamos de una conducta que ya ha sido regulada o que podría ser sometida a una modificación, derogación o entrar en conflicto con otra disposición perteneciente al mismo sistema normativo. De esta manera, bajo la distinción entre el permiso débil y el permiso fuerte se pueden concluir dos cosas: 1) el permiso fuerte solo en el supuesto (i) incluye el permiso débil; 2) el permiso fuerte según

(24) 'Una de las enseñanzas fundamentales que se pueden extraer del análisis de Alchourrón y Bulygin es que la expresión 'completitud' es ambigua y que solo uno de los modos de entenderla puede constituir un ideal racional con relación al derecho. El postulado o dogma de completitud, a pesar de ser una idea muy extendida, es doblemente criticable. En primer lugar, porque asume como un ideal algo que es una ilusión inalcanzable: la solución de todos los casos posibles. En segundo lugar, porque asume como una propiedad necesaria de todo sistema normativo aquello que solo es una propiedad contingente: la ausencia de lagunas" (Redondo, 2006, p. 304).

(25) Entendidas como formulaciones normativas interpretadas, en tanto los procesos de identificación o explicitación de estas normas (pertenecientes al sistema) han culminado. Valga esta precisión para evitar entrar nuevamente en la discusión que plantean Bayón y Ruiz Manero, sobre la importancia de distinguir entre calificaciones normativas expresas o prima facie y calificaciones normativas concluyentes o definitivas, con la cual pretenden demostrar que existe equivalencia pragmática entre la ausencia de regulación y la regulación permisiva. 
el supuesto (ii) podría generar conflictos normativos en un determinado sistema.

Con el propósito de complementar el análisis de von Wright y corregir algunos errores de su teoría, como, por ejemplo, considerar que el permiso fuerte implica el permiso débil y que el permiso fuerte es un concepto prescriptivo o un carácter normativo, A\&B (1991, p. 218) vieron necesario efectuar la distinción entre el uso prescriptivo y descriptivo de los términos deónticos "permitido" y "prohibido":

- Cuando una norma contiene el término "prohibido" expresa un concepto prescriptivo de prohibición, es decir, es una norma que prohíbe. En cambio, cuando una proposición normativa contiene el término "prohibido" expresa un concepto descriptivo de prohibición, es decir, se afirma que una determinada conducta está prohibida por un sistema normativo.

- Cuando una norma contiene el término "permitido" expresa un concepto prescriptivo de permisión, es decir, es una norma que permite. En cambio, cuando una proposición normativa contiene el término "permitido" el resultado es ambiguo, pues afirmar que una conducta está permitida por un sistema normativo puede significar dos cosas: a) que la conducta está permitida por una norma (permiso fuerte); o, b) que dicha conducta no está prohibida (permiso débil).

En ese sentido, de conformidad con A\&B habría tres conceptos de permisión: un concepto de "permisión prescriptiva" y dos conceptos de "permisión descriptiva" (permiso fuerte y permiso débil). Por ello, A\&B consideran que la teoría de von Wright no tomó en cuenta que los términos deónticos "permitido" y "prohibido" tienen significados diferentes cuando se usan en los planos prescriptivo y descriptivo; pasar por alto esto puede llevarnos a creer que el permiso fuerte implica el permiso débil o una conducta no prohibida, lo cual no es cierto en todos los casos, como tampoco lo es que el permiso fuerte sea un concepto prescriptivo o un carácter normativo, pues solo lo sería la norma permisiva.

Dado que la norma permisiva es un concepto prescriptivo, solo ella podría ser sometida a derogación, y esto no podría suceder con los otros dos conceptos de permisión (el permiso fuerte y débil) por tratarse de proposiciones normativas. En ese sentido, si una norma permisiva es dejada sin efecto, habría sido pasible de una derogación; pero si una conducta o estado de cosas no regulada pasa a ser prohibida o permitida mediante una norma, habría sido extraída de la esfera extranormativa.

En el ámbito judicial, la existencia de permisos débiles, o simplemente, conductas no reguladas, también genera controversia, puesto que los jueces pueden prohibir conductas no prohibidas y ordenar conductas no obligatorias. Parte de la doctrina fundamenta dicho proceder señalando que ante la ausencia de norma, los jueces tienen un poder discrecional consistente en admitir la demanda y condenar, o rechazar la demanda y absolver ${ }^{(26)}$. Lo cierto es que el tratamiento es diferente cuando los jueces se encuentran ante conductas reguladas como no prohibidas o no obligatorias, es decir, ante normas preexistentes (Bulygin, 2010, p. 294-295).

\subsection{La tesis refleja y el ideal de completitud y coherencia de los sistemas normativos} En conexión con la tesis refleja se puede ver que, si bien los conceptos prescriptivos son interdefinibles, en el sentido que una norma que prohíbe es una norma que no permite, y una norma que permite es una norma que no prohíbe, no sucede lo mismo con los conceptos descriptivos. La permisión descriptiva débil y la prohibición descriptiva son interdefinibles por ser contradictorias, pero la permisión descriptiva fuerte y la prohibición descriptiva no lo son, dado que una conducta permitida por el sistema normativo no siempre será equivalente a una conducta no prohibida por dicho sistema o viceversa, debido a lo siguiente:

Primero, la conducta podría estar permitida en sentido fuerte y prohibida a su vez, lo que configuraría un conflicto normativo, haciendo que el sistema sea incoherente.

Segundo, la conducta podría estar no permitida ni prohibida en sentido fuerte por tratarse simplemente de una conducta

(26) Si bien mi investigación no abordará el tema de la discreción judicial en relación a las permisiones, es importante señalar que la existencia de conductas negativamente permitidas genera algunas consecuencias en el ámbito de la justificación de las decisiones judiciales, en lo que se refiere específicamente a la actuación de los jueces frente a las lagunas normativas, pues en estos casos se plantea la tesis de que el juez está en la posición de decidir discrecionalmente. El razonamiento es el siguiente: el juez no tiene discreción frente a normas que permiten una determinada conducta; pero, en los casos en los que no existe ninguna norma en el sistema que diga algo respecto a la conducta del demandado, el juez no tiene una obligación específica de admitir o rechazar la demanda, por lo tanto, el juez tiene discreción para decidir. Esta tesis, defendida por A\&B (2010) y Navarro (2011), ha sido materia de un amplio debate, pues existen autores como Bayón (2009) y Ruiz Manero (2015) que niegan que los jueces tengan discreción en casos de conductas negativamente permitidas y que haya simetría entre sentencias condenatorias y denegatorias. 
La importancia del concepto de permisión en los sistemas normativos y en el marco de los estados constitucionales

The importance of the concept of permission in the normative systems and the framework of constitutional states

no regulada. En este caso, se podrían presentar tres situaciones:

a) Que la conducta no prohibida no tenga propiedades relevantes, dando lo mismo para el derecho si la conducta se hace o no se hace, por lo que se trataría de una indiferencia normativa.

b) Que la conducta no prohibida tenga propiedades relevantes, pero no sea posible concretizarla sin regulación, por lo que se trataría de una laguna normativa.

c) Que la conducta no prohibida tenga propiedades relevantes y se encuentre disponible para el sujeto aún sin regulación; este es el único caso en el que se podría decir que existe una equivalencia pragmática entre el permiso (débil) y la conducta no regulada.

Salvo la situación descrita en el punto c), los demás casos mostrarían que la tesis de la equivalencia pragmática entre la no prohibición y la regulación jurídica, sostenida por autores como O\&W, Ruiz Manero y Bayón, y que consiste en creer que todas las conductas no prohibidas se encuentran jurídicamente permitidas por el derecho y disponibles para los sujetos, no se condice con la práctica de los sistemas jurídicos y con la necesidad de propiciar la efectiva realización de las conductas que se consideran permitidas.

Por ejemplo, en el punto b) se puede apreciar que la acción a que se refiere el permiso no se encuentra disponible para el sujeto ${ }^{(27)}$, y nada asegura que ante una acción judicial este logre dicho reconocimiento, pues al tratarse de una conducta no regulada, el juez tiene discrecionalidad para resolver. Esto se opone a lo señalado por Ruiz Manero $(2017$, p. 2), en el sentido que la relevancia de las disposiciones permisivas puede explicarse enteramente en términos de reglas prohibitivas, o que la existencia de una norma permisiva y la ausencia de una norma prohibitiva son situaciones equivalentes.

En ese sentido, la distinción entre permisos fuertes y permisos débiles, y los tres conceptos de permiso según su uso prescriptivo y descriptivo, explicarían por qué los sistemas normativos no son completos y coherentes, salvo que asumamos ello como un ideal(28). En efecto, si suprimimos la existencia de una esfera extranormativa, lo que proponen imperativistas como O\&W, generamos la ilusión de que los sistemas normativos son completos y coherentes, y a su vez convertimos en inoficiosa la regulación de las conductas con propiedades relevantes para el derecho (A\&B, 1991, p. 220, 231), es decir, convertimos el derecho en un concepto estático.

Sin embargo, no es verdad que el permiso fuerte implica el permiso débil, pues es posible que el mismo estado de cosas esté permitido en sentido fuerte y prohibido a su vez (A\&B, 1991 , p. 220); y estas contradicciones hacen que los sistemas normativos puedan ser incoherentes. Lo señalado no excluye la posibilidad de que existan conductas o estados de cosas permitidos en sentido fuerte que también estén permitidos en sentido débil, es decir, que en esos casos no existan conflictos normativos; pero esto no desaparece la ambigüedad del principio de permisión.

Un sistema normativo es completo en tanto todas las conductas y estados de cosas con propiedades relevantes estén regulados por dicho sistema, no dando cabida a la existencia de lagunas normativas; en otras palabras, en un sistema completo no deberían existir conductas o estados de cosas permitidos en sentido débil que no estén a su vez permitidos en sentido fuerte. Asimismo, un sistema normativo es coherente en tanto no existan en él conflictos normativos; esto se puede interpretar de dos maneras: a) que ninguna conducta o estado de cosas está prohibido y a la vez permitido en sentido fuerte; $y, b)$ que todas las conductas o estados de cosas permitidos en sentido fuerte están permitidos en sentido débil. Tal como hemos visto, ambos supuestos son un ideal(29).

Por otro lado, mantener como argumento la existencia de sistemas normativos completos y coherentes parecería llevarnos a sostener

(27) Desde mi punto de vista, no basta con que la posible realización de la acción permitida no suponga la violación de ninguna norma del sistema.

(28) Aunque Ruiz Manero (2017, p. 1-2) considera que la distinción entre permisos fuertes y débiles es útil y clarificadora, señala que esta no tiene el alcance o la importancia que Bulygin le atribuye, y que más bien esta distinción sería fructífera si fuese complementada con otras dos distinciones: entre permisos protegidos y no protegidos, y entre permisos concluyentes y prima facie, las que también han sido desarrolladas por Bayón (2009).

(29) Para Cristina Redondo (2006), un ideal de completitud absoluta de los sistemas jurídicos es lógicamente posible solo bajo dos formas: desde un enfoque formalista, mediante la introducción de reglas residuales de clausura; o desde un enfoque moralista, aceptando que la propiedad de justicia o la corrección moral son condición suficiente de pertenencia al sistema normativo, es decir, como un criterio extra-sistemático de validez. Ambos enfoques son contradictorios y harían inconsistente el sistema. 
implícitamente que la función legisladora del Estado es una cuestión acabada, pues no tendría sentido la introducción de normas nuevas en tanto las interpretaciones jurídicas podrían suplir perfectamente la regulación de las conductas; sin embargo, la realidad demuestra que los sistemas jurídicos no operan de esta manera.

Por último, si bien los procesos de identificación o explicitación de las normas que se llevan a cabo a través de la aplicación de técnicas de interpretación, son necesarios para completar la labor que realizan los tribunales, estos no pueden equipararse con la regulación normativa; con esto no se pretende desconocer la importancia de los principios y el hecho de que en ciertos casos estos puedan salvar la falta de una norma específica, pero nada dice que debido a la aplicación de los mismos, los sistemas normativos son completos y cerrados.

\subsection{Interpretación de la tesis refleja a la luz de la distinción entre permisos fuertes y débiles}

Mi planteamiento es que es posible demostrar que pueden existir conductas o estados de cosas con propiedades relevantes que no están regulados por un sistema normativo (lagunas normativas), haciendo que este sea incompleto, o que pueden existir normas contradictorias en un mismo sistema (conflictos normativos), haciendo que este sea incoherente, sin que ello signifique rechazar la tesis de la interdefinibilidad de los términos deónticos "prohibido" y "permitido". Pero, entonces, cabría preguntarnos cómo debemos interpretar el principio "lo que no está prohibido está permitido".

De la argumentación presentada en el apartado anterior se pueden derivar tres posibles interpretaciones (A\&B, 1991, p. 221):

a) Permitido como concepto prescriptivo: El principio es una norma permisiva con un contenido especial. Cuando una norma de este tipo es agregada al sistema, la conducta o estado de cosas regulado puede calificarse como completo o cerrado.

b) Permitido en sentido fuerte: El principio es una proposición contingente acerca de un sistema normativo, por lo tanto, de por sí no puede invocarse para sostener que todos los sistemas normativos son completos.

c) Permitido en sentido débil: El principio es analítico y su contenido dependerá de la definición de permiso débil, pero este en realidad no nos dice nada acerca de un sistema normativo en particular, salvo que se trata de conductas que no están permitidas en sentido fuerte, lo que también podría significar que son conductas no reguladas o no prohibidas.

En ese sentido, corresponde decir que el concepto de permisión no puede expresarse siempre en términos de prohibición, sino solo en ciertos casos. En esa línea, Bulygin (2010, p. 290) señala que: “(..) una cosa es que en ciertas situaciones la ausencia de regulación y la permisión sean equivalentes para el sujeto y otra muy distinta que haya una equivalencia pragmática en todas las situaciones (...)".

Por ejemplo, que no esté prohibido (o regulado) que las personas puedan sentarse en los parques ubicados dentro de la ciudad de Lima, es equivalente a que dicha conducta esté permitida, en tanto la regulación permisiva de dicha conducta quizás no introduciría nada nuevo para quien desee llevar a cabo la misma. En cambio, que no esté prohibido (o regulado) que toda persona con VIH/SIDA en situación de vulnerabilidad o pobreza extrema, pueda solicitar atención integral (provisión continua de la totalidad de requerimientos médicos, tales como exámenes, medicinas, tratamientos, etc., para superar las consecuencias de la enfermedad) en cualquier hospital ubicado dentro del territorio peruano, no es equivalente a que dicha conducta esté permitida en términos prácticos; aquí la regulación permisiva de dicha conducta sí introduciría algo nuevo a favor del sujeto, que sería la obligación del Estado de facilitar dicho acto o una prohibición de interferencia, esto se podría traducir en una asignación presupuestal adicional en materia de salud, la ejecución de un plan de focalización para identificar aquellos sectores sin cobertura y con altos índices de pobreza, incrementar la contratación de personal médico, la adquisición de medicinas para el tratamiento de este tipo de pacientes, entre otros.

En ese sentido, el análisis de las normas como entidades puramente conceptuales (independientes del lenguaje) y el análisis pragmático de las permisiones no son mutuamente excluyentes, tal como plantean Riccardo Guastini, Alejandro Calzetta y Alessio Sardo.

Al respecto, en un estudio reciente Guastini $(2017$, p. 2) señala que se cree que la concepción semántica y la concepción pragmática brindan dos soluciones distintas al problema ontológico de las normas, cuando en realidad este problema encierra dos cuestiones distintas referidas a: (i) las condiciones que hacen que una norma exista (el proceso de producción de las 
normas), y (ii) el tipo de entidad que es una norma (la naturaleza del producto de dicho proceso). Para Guastini, cada una de estas dos concepciones solo puede brindar respuesta a una de las mencionadas cuestiones, pero no a las dos: la tesis pragmática resolvería la cuestión de la génesis de las normas; y la tesis semántica, la cuestión de su naturaleza. Visto de esta manera por dicho autor, ambas tesis no son necesariamente incompatibles o antagónicas -como en su momento señalaran A\&B (1991, p. 122-126), sino más bien complementarias.

Asimismo, tal como refieren Calzetta \& Sardo (2014, p. $49,59)$, en algún punto es engañoso concebir a las normas simplemente como el resultado de operaciones sobre proposiciones, pues esto nos puede llevar a confundir una norma con su formulación descriptiva o con el enunciado que la expresa. De igual forma, si las normas fuesen independientes del lenguaje, entonces no dependerían de acciones humanas o de hechos empíricos, no serían postulados humanos ni el significado de formulaciones normativas, sino simplemente significados, precederían a la legislación y las fuentes legales que conocemos dejarían de existir.

Conforme a lo expuesto, es posible sostener como lo hace Guastini (2017, p. 5), que: a) las normas son los significados de enunciados usados para prescribir; $y, b$ ) las normas no pueden existir sin enunciados que las expresen o actos de lenguaje.

En efecto, si aceptamos que una norma es distinta a la formulación que la expresa y que no todas las proposiciones o actos de habla producen una contradicción, porque los actos de habla no son simples operaciones sobre proposiciones (Calzetta \& Sardo, 2014, p. 51), y así también que el uso prescriptivo y descriptivo de los términos deónticos "permitido" y "prohibido" tiene significados diferentes (A\&B, 1991, p. 218), entonces no es posible sostener el reduccionismo del concepto de permisión o solo aceptar que este reduccionismo podría darse en ciertos casos.

Por lo tanto, otra de mis conclusiones es que no es posible generalizar el reduccionismo del concepto de permisión; no obstante, también considero que demostrar la autonomía y relevancia de las normas permisivas significa ir mucho más allá de una discusión puramente conceptual.

\section{La importancia de las normas permisivas}

Existen autores que niegan la importancia de los permisos fuertes y la existencia de una esfera extranormativa, otros plantean una equivalencia pragmática entre la ausencia de regulación, la no prohibición y la permisión; no obstante, al mismo tiempo, algunos de estos autores afirman que los permisos cumplen la función normativa de derogar una prohibición, exceptuar una prohibición, aclarar los casos que no están comprendidos dentro de los alcances de una prohibición e introducir una prohibición a las autoridades subordinadas.

¿Es cierto, entonces, que las reglas permisivas no cumplen ningún papel relevante en los sistemas normativos, aun cuando estas puedan explicarse en términos de prohibición, derogación, excepción o definición?

\subsection{Funciones de las reglas permisivas en los sistemas normativos, y en el marco de los estados constitucionales}

Los filósofos polacos O\&W (1973, 1986, 1991), que propugnan un imperativismo radical, plantean argumentos en contra de la teoría de los permisos fuertes y débiles, y de la importancia de las normas permisivas, señalando que el concepto de permiso no tiene un carácter normativo, sino que es una categoría normativa derivada o incluso superflua, por tanto, no desempeña un papel esencial en el análisis de los sistemas normativos. Los dos errores en los que se incurre para sostener la teoría de los permisos fuertes y débiles, sostienen estos autores, refieren: (i) que las normas permisivas son una categoría autónoma de las normas de prohibición; y, (ii) que el universo de los actos humanos puede dividirse en dos esferas, una normativa y otra extranormativa.

Respecto de (i), O\&W se oponen señalando que "lo que está permitido" constituye una suerte de conductas indiferentes para los sistemas normativos, por lo que la introducción del concepto de permiso fuerte no sería otra cosa que una indiferencia fuerte que no provee información normativa relevante, en tanto dicha información está contenida en obligaciones y prohibiciones. De manera que, si una autoridad dice "permito un acto $A$ el cual hasta ahora estuvo prohibido", desde el imperativismo que propugnan estos autores, esto significa "ordeno que $A$ sea considerado indiferente". En cuanto a (ii), dichos autores rechazan esta idea señalando que no es posible que " $x$ " pertenezca al sistema normativo y la negación de " $x$ " (su prohibición) no, es decir, que pertenezca a la esfera extranormativa (conducta no regulada), pues incluso lo extranormativo se deriva de lo normativo. 
Conforme a las respuestas de O\&W a (i) y (ii), se propone reemplazar el concepto de permiso por el concepto normativo de indiferencia. Asimismo, O\&W señalan que, si se acepta que los sistemas normativos son inconsistentes o incoherentes siguiendo el razonamiento de $A \& B$, entonces cualquier oración podría pertenecer a las consecuencias de dichos sistemas. Tampoco aceptan que, conforme a los criterios de A\&B, para que los sistemas normativos sean consistentes o coherentes, el permiso fuerte tenga que implicar el permiso débil, es decir, la no regulación de la negación de x como condición necesaria para que " $x$ " esté permitida( ${ }^{(30)}$.

Sin embargo, O\&W se preguntan por qué la negación de " $x$ " debe estar no regulada, mientras que la negación del acto de indiferencia sí; les parece más lógico aceptar que si " $x$ " es un permiso fuerte entonces la negación de " $x$ " también lo es, con lo cual la distinción entre la indiferencia y el permiso fuerte sería solo verbal:

"( ) la tarea de la regulación normativa es la división del universo de actos en algunas esferas. A la luz de la lógica deóntica estándar esta división es generada por "obligación" (o "prohibición"), y no por "indiferencia"; por "permisos débiles" solo en caso que nosotros sepamos la división de ellos en "obligación" e "indiferencia". Las categorías de obligación, prohibición, permiso (débil) e indiferencia agotan, en nuestra opinión, el vocabulario lógico de los deónticos. En resumen, en vista de las dificultades lógicas-semánticas y las complicaciones derivadas de la aceptación de los permisos fuertes, preferimos la reducción del vocabulario lógico de los deónticos a la obligación y la negación (el cual es suficiente para definir los conceptos restantes)" (O\&W, 1986, p. 86-87).

No obstante, pienso que cuando O\&W sostienen que "si una conducta " $x$ " pertenece a un sistema normativo, entonces la negación de " $x$ " también debería pertenecer a ese sistema normativo", confunden el permiso bilateral o la indiferencia con la esfera extranormativa, espacio donde se encuentra el conjunto de conductas y estados de cosas no regulados.

En efecto, de acuerdo al concepto de indiferencia que manejan dichos autores, existe una norma que permite " $x$ " $y$ una norma que permite la negación de " $x$ ", por lo tanto, " $x$ " $y$ la negación de " $x$ " están permitidos en sentido fuerte y el sistema normativo es completo y coherente respecto de dicha conducta. Esto es distinto a la esfera extranormativa, pues en este caso no existe en el sistema normativo ninguna norma referente a " $x$ " $y$ la negación de " $x$ ", es decir, tanto " $x$ " y la negación de " $x$ " no están regulados, por lo que ambos están permitidos en sentido débil (o no prohibidos), pudiéndose decir que en relación a dicha conducta el sistema normativo es incompleto.

A mi parecer, la afirmación de A\&B de que la conducta regulada por el permiso fuerte deba ser un permiso débil o una conducta no regulada, tiene lógica si lo que se pretende es propender a la coherencia de los sistemas normativos; sin embargo, la práctica de los sistemas demuestra que es posible que existan conductas permitidas que a su vez estén prohibidas, es decir, casos de conflictos normativos.

En ese sentido, si bien la situación de los actos no regulados depende de los actos regulados y de los cambios del sistema normativo, y algunos actos no regulados pueden ejercerse bajo una interpretación extensiva del principio de libertad, ello no quiere decir que los actos no regulados tienen la misma naturaleza y los mismos efectos que los actos regulados.

Asimismo, como mencionan A\&B (1991, p. 234-235), desmerecer la importancia de las normas permisivas surge del error de confundir su "analizabilidad" con su existencia, pues si bien es cierto que las normas permisivas pueden analizarse en términos de prohibición, esto no quiere decir que por ello dejen de ser permisivas. Tampoco sería correcto, desde el punto de vista lógico, reducir las normas permisivas a normas de prohibición y a su vez sostener que la función normativa de las normas permisivas es establecer excepciones a las normas de prohibición, pues implícitamente se estaría reconociendo que las normas permisivas cumplen la importantísima función de levantar prohibiciones y derogar normas de prohibición, lo que se considera un acto normativo totalmente distinto al acto normativo de prohibir.

(30) Al respecto, A\&B (1991, p. 217-218) explican que una de las definiciones de permiso fuerte introducidas por von Wright señala que un acto "está permitido en el sentido fuerte si no está prohibido, pero está sometido a norma", y que la condición referida a que "el acto no ha de estar prohibido" tiene por objeto prevenir la existencia de conflictos normativos. Por ejemplo, si decimos que existe una norma que permite fumar en espacios públicos, entonces -según lo planteado por A\&B- fumar en espacios públicos y no fumar en espacios públicos debería tratarse de conductas no reguladas (ni como prohibidas ni como obligatorias, respectivamente). Dichos autores también señalan que de todos modos parece razonable aceptar la posibilidad de conflictos dentro de un sistema normativo, con lo cual no sería verdad que el permiso fuerte implica el permiso débil, como sostenía von Wright, o no en todos los casos. 
De acuerdo a lo anterior, es necesario señalar cuáles serían las diferencias prácticas entre la autorización que surge de una norma permisiva y la ausencia de restricciones que se produce en casos no regulados por el derecho (Navarro, 2011, p. 110), a efectos de demostrar que la importancia de las normas permisivas no solo se reduce a que cumplen un fin motivacional, sino que principalmente cumplen funciones relacionadas con la clausura y coherencia de los sistemas normativos, la eficacia de los derechos y la jerarquía normativa.

\subsection{La clausura de los sistemas normativos}

Si bien para autores como Francesca Poggi (2004, p. 13) existen al menos dos sentidos en que un carácter normativo puede ser definido como autónomo: en un sentido lógico significa "no interdefinibilidad" o no definible en términos de otros caracteres normativos, y en un sentido semántico significa "no traducible semánticamente" a enunciados que expresan un diferente carácter normativo; pienso que es posible señalar la autonomía de las normas permisivas por la importancia que tienen en la estructuración y el funcionamiento de los sistemas jurídicos. En efecto, para autores como Pablo Navarro (2011, p. 114), las normas permisivas cumplen la función normativa de autorizar conductas y clausurar el sistema normativo sin introducir incoherencias; de esta manera, cumplen una función irremplazable que no puede lograrse a través de otras normas.

Para Navarro, el problema de las normas permisivas no radicaría tanto en su autonomía conceptual, pues ciertamente es posible autorizar conductas por medios diferentes y mediante otras pautas normativas, sino en la utilidad, conveniencia y simplicidad de su uso. Esta perspectiva es interesante porque no busca responder si los sistemas normativos son cerrados o completos (pues claramente no lo son), sino cómo se puede lograr que lo sean ${ }^{(31)}$.

La clausura es una manera de completar un sistema jurídico con la finalidad de eliminar lagunas normativas. Una autoridad puede cerrar un sistema mediante una norma de clausura que cubra todos los supuestos que antes se encontraban sin regulación; para esto, de conformidad con $A \& B$, una norma de clausura debe cumplir con las siguientes condiciones: (i) tiene que clausurar el sistema, es decir, completarlo; y, (ii) tiene que preservar la coherencia del mismo.
Las reglas de clausura que "prohíben" u "ordenan" las acciones no normadas por el sistema no son posibles porque derivan en contradicciones: una regla de clausura prohibitiva generaría incoherencias al establecer "Php" (prohibido p) y "Ph-p" (prohibido "p); lo mismo sucedería con una regla de clausura obligatoria al establecer "Op" (obligatorio $p$ ) y "O-p" (obligatorio ' $p$ ), más aún cuando de "Op" se puede inferir "Pp" (permitido $p$ ).

En cambio, la regla de clausura permisiva es compatible con la coherencia porque no genera contradicciones al establecer "Pp" (permitido p) y "P-p" (permitido 'p). En ese sentido, y tal como señalaron A\&B (1987, p. 195), la norma permisiva ocuparía una posición privilegiada en los sistemas normativos al ser la única forma de evitar las lagunas, debido a que es el único carácter deóntico que pueden calificar una acción y su negación sin que se produzcan incoherencias en los sistemas. Esto demostraría que las normas permisivas no pueden reducirse a otros modos de regular la conducta (Navarro, 2011, p. 116).

Cabe señalar que la necesidad de coherencia de los sistemas normativos no solo es consecuencia de un ideal de racionalidad, sino también, como señala Navarro (2011, p. 126), de un compromiso con los ideales y valores del Estado constitucional de derecho (por ejemplo, el principio de separación de poderes y el principio de motivación de las decisiones judiciales), ámbito en el que es frecuente utilizar normas de clausura como una garantía de los individuos, a fin de limitar las intervenciones del Estado en aquellas situaciones que no se encuentran reguladas.

Por eso, si bien aún hoy sigue siendo materia de discusión teórica la validez general del principio de permisión como norma de clausura en los sistemas jurídicos ${ }^{(32)}$, es

(31) En relación a esto, Cristina Redondo (2006, p. 315) señala que una de las formas de alcanzar el ideal de completitud absoluta de los sistemas jurídicos es mediante la introducción de reglas residuales de clausura: "En resumen, la presencia de una NRC [norma residual de clausura] en un sistema a puede juzgarse contingente, pero lo que me interesa sostener aquí no es que los sistemas jurídicos son siempre cerrados porque incluyen necesariamente una norma de este tipo, sino que ello podría ser el caso, y que la clausura absoluta que se lograría mediante la incorporación de una norma residual como la señalada no generaría ningún problema de coherencia".

(32) Para Echave, Urquijo y Guibourg (1986, p. 154), el principio de permisión constitucional ("nadie está obligado a hacer lo que la ley no manda, ni impedido de hacer lo que ella no prohíbe") puede interpretarse como una regla de clausura que dispone la permisión expresa de todo lo que las demás normas no prohíben: "una regla de clausura 'liberal', entre otras posibles. En efecto, así corno ella dice que todo lo no normado (y por ello no prohibido) está permitido, podría decir -por ejemplo- que todo lo no normado (y por ello no permitido) está prohibido, con lo que el orden normativo se parecería más a un régimen carcelario. ¿Todo se reduce, entonces, a una elección valorativa (y legislativa) entre normas de clausura?" 
posible lograr cierto consenso sobre la existencia de reglas de clausura permisiva ${ }^{\left({ }^{33}\right)}$ en determinados sectores o ámbitos del derecho como, por ejemplo, el sancionador. Esto se desprende de la clásica distinción entre la esfera del derecho privado, en el que vale el principio "todo está permitido excepto lo que está expresamente prohibido"; y la esfera del derecho público, en el que vale el principio "todo está prohibido excepto lo que está expresamente permitido".

Como bien sabemos, en el ámbito del derecho penal y administrativo sancionador rigen los principios de legalidad y taxatividad como garantía de la libertad individual y del ejercicio razonable del poder público ${ }^{(34)}$. En ese sentido, toda conducta que no esté legal y taxativamente tipificada como un delito, falta o infracción administrativa, está, desde el punto de vista penal y administrativo, permitida, por lo que no será pasible de sanción. Al respecto, Iturralde (1991, p. 212) señala que: "Toda acción u omisión cuya consecuencia no constituya delito, falta, medida de seguridad o infracción administrativa según la legislación vigente en el momento de su comisión, no puede ser sancionada con ninguna de esas consecuencias".

Por su parte, Ruiz Manero (2005, p. 119-120; 2015, p. 5152) sostiene que el ámbito sancionador (penal y administrativo) consiste en un sistema de prohibiciones ${ }^{(35)}$, y como tal se conforma exclusivamente por reglas; además, se trata de un conjunto de reglas cerrado pues no permite la ampliación de prohibiciones sin la existencia de una norma. Para mayor detalle, dicho autor precisa que el ámbito sancionador, específicamente el penal, incorpora a través de la exigencia de tipicidad de los delitos una regla general excluyente o regla de clausura: "la regla de clausura implicada por el principio de tipicidad penal involucra que están penalmente permitidas todas aquellas acciones (...) que no están cubiertas por algún tipo penal". Por último, señala que: "(...) en el derecho penal, si una conducta no está expresamente prohibida en una regla entonces está, desde el punto de vista del derecho penal, permitida sin necesidad de deliberación o ponderación alguna".

En ese sentido, la ausencia de regla en el ámbito sancionador implica que la conducta en cuestión resulte definitiva o concluyentemente permitida (regla de clausura permisiva), lo cual marca una diferencia fundamental con otros sectores del derecho, como el privado. De esto se deriva que el derecho penal, como sistema de prohibiciones, no contenga lagunas. Sobre estos dos temas, Iturralde (1991, p. 214) precisa lo siguiente: (i) en el ámbito sancionador la permisión no debe entenderse respecto a las conductas o comportamientos, sino a sus consecuencias, dado que es posible que una conducta no sea pasible de sanción penal o administrativa, pero esto no necesariamente excluye una consecuencia de otra naturaleza (civil, laboral, etc.); y, (ii) la validez del principio de permisión en el ámbito sancionador no significa que este se encuentre exento de lagunas normativas, es decir, de conductas antijurídicas que no se encuentran tipificadas penalmente (por ejemplo, la eutanasia, que carece de regulación penal en algunos sistemas normativos).

Respecto de (i), al parecer Iturralde olvida que solo las conductas pueden ser

(33) Una regla de clausura permisiva es lo que Cristina Redondo (2006, p. 313) denomina como una norma residual de clausura (NRC): "Una NRC tiene dos lecturas posibles. En una lectura, es una meta norma que declara positivamente irrelevante toda propiedad que no sea prevista por las específicas normas del sistema con relación a las soluciones que dichas normas establecen. En una segunda lectura es una norma primaria que regula de forma uniforme y categórica el comportamiento de sus destinatarios. Por ejemplo, supongamos una NRC que faculta cualquier comportamiento que no haya sido regulado de otro modo por las normas específicas del sistema. Tal norma indica que las únicas propiedades que pueden ser tenidas en cuenta para obtener una conclusión normativa sobre la base del sistema son aquellas que las normas específicas prevén, y con relación a las acciones que tales normas califican deónticamente. Por este motivo, puede decirse que la NRC declara positivamente irrelevante toda propiedad, salvo aquellas previstas por las específicas normas del sistema con relación a las acciones que ellas específicamente regulan. Pero al mismo tiempo, ello significa que toda acción, que no sean las acciones reguladas por las normas específicas del sistema y bajo las condiciones previstas por las mismas, queda categóricamente permitida".

(34) El principio de legalidad exige que los delitos estén establecidos por ley y que las conductas prohibidas se encuentren claramente delimitadas, debido a esto no está permitida la aplicación por analogía y el uso de cláusulas generales e indeterminadas en la tipificación de las prohibiciones. Asimismo, los principios de culpabilidad, legalidad, tipicidad, entre otros que suelen corresponder al derecho penal, constituyen principios básicos del derecho sancionador, por lo que también son aplicables al derecho administrativo. En cuanto al subprincipio de tipicidad o taxatividad, este constituye una de las manifestaciones o concreciones del principio de legalidad que exige al legislador que las prohibiciones que conllevan sanciones, sean estas penales o administrativas, estén redactadas con un nivel de precisión suficiente que permita a cualquier ciudadano de formación básica comprender sin dificultad lo que se está proscribiendo (Fundamentos 4 y 5 de la Sentencia recaída en el Expediente 2192-2004-AA/TC).

(35) Cabe precisar que, aunque el derecho penal encierra un conjunto de conductas en su mayoría prohibidas, también se conforma excepcionalmente por normas que regulan conductas exentas de sanción penal, como, por ejemplo, la legítima defensa, la no autoincriminación o el encubrimiento personal o real de persona con la que se tiene una relación cercana. 
calificadas deónticamente, y que el derecho penal se encuentra conformado por conductas calificadas como prohibidas, por lo tanto, la conducta que no es típica se encuentra penalmente permitida. Al respecto, A\&B (1987, p. 198) han señalado que:

"La regla nullum crimen sine lege puede entenderse también como una regla de clausura que permite todas las conductas no prohibidas por el sistema penal, es decir, autoriza a inferir la permisión de una conducta (en un caso dado), si del sistema no se infiere ninguna prohibición de esa conducta (en ese caso). (...) En consecuencia, pues, se podría enunciar la regla de clausura del siguiente modo: 'Todo lo que no está penalmente prohibido, está penalmente permitido'. Que un acto esté penalmente permitido significa que su realización no acarrea sanciones penales, pero no excluye en modo alguno la prohibición por algún otro tipo de norma ( )".

En efecto, si bien es posible que una conducta esté penalmente permitida pero prohibida en otro ámbito del derecho como el civil, supuesto que Iturralde nos plantea, ello no significa que la conducta que no es típica no esté permitida penalmente; no obstante, dicha situación puede acarrear desde el punto de vista lógico contradicciones o antinomias ${ }^{(36)}$ en los sistemas jurídicos. Este sería el caso, por ejemplo, de los actos prohibidos al interdicto ${ }^{(37)}$; si bien tales actos estarían permitidos en el ámbito penal (al no estar tipificados), los mismos podrían ser sometidos a anulación por la vía civil(38). La antinomia que podría surgir del presente caso se resolvería a través de la aplicación del criterio de lex especialis ${ }^{(39) .}$

Respecto de (ii), habría que decir que no resulta lógico admitir que el derecho penal es un sistema cerrado y a su vez señalar que este tiene lagunas normativas, como refiere Iturralde, dado que toda conducta jurídica concebible por el derecho penal se encuentra regulada por este o cuenta con una solución, en el sentido que si la conducta es típica entonces le corresponde una pena, y si la conducta no es típica entonces no le corresponde una pena ${ }^{(40)}$.

En cuanto a los ejemplos señalados por Iturralde sobre conductas que no se encuentran tipificadas penalmente, pero que para el intérprete deberían estarlo (porque existen razones de naturaleza social para ello, otros sistemas jurídicos sí las regulan, etc.), estas no serían lagunas normativas sino que podrían considerarse lagunas axiológicas ${ }^{(41)}$. Sin embargo, siendo que en materia penal las posibilidades de interpretación del juez se encuentran limitadas por el principio de legalidad, el cual, conforme a lo señalado anteriormente, se considera una regla de clausura, solo quedaría que la sociedad haga presión ante el poder legislativo para que dichas conductas sean tipificadas penalmente en un futuro ${ }^{(42)}$.

\subsection{La libertad normativa de elegir}

Una de las objeciones a la tesis de la equivalencia pragmática sostiene que con ella existiría la creencia de que cualquier permiso conlleva la obligación de los demás de abstenerse de impedir la realización de la conducta permitida, cuando dicha obligación de abstención solo podría provenir de una norma que la imponga expresamente o de una

(36) Las antinomias son situaciones en las que hay más de una regla aplicable y estas resultan lógicamente incompatibles entre sí; o, en otras palabras, existe una antinomia siempre que para un determinado supuesto de hecho estén previstas dos consecuencias jurídicas incompatibles por dos normas diversas pertenecientes al sistema jurídico. Cabe precisar, tal como señala el profesor Guastini (1999, p. 437), que una antinomia es un conflicto entre normas y no entre disposiciones normativas. Algunas antinomias pueden resolverse atendiendo a principios que gravitan en el ámbito de la interpretación y a otras consideraciones que tienen que ver con la ponderación entre principios. Los criterios básicos aplicables son tres: lex superior o criterio jerárquico, lex posterior 0 criterio cronológico, y lex especialis o criterio de especialidad (Ruiz Manero, 2015, p. 60).

(37) Artículo 591 del Código Civil del Perú. Actos prohibidos al interdicto. El pródigo, el mal gestor, el ebrio habitual y el toxicómano no pueden litigar ni practicar actos que no sean de mera administración de su patrimonio, sin asentimiento especial del curador. $\mathrm{E}$ juez, al instituir la curatela, puede limitar también la capacidad del interdicto en cuanto a determinados actos de administración.

(38) Artículo 594 del Código Civil del Perú. Acción de anulación de actos prohibidos al interdicto. Las personas que pueden promover la declaración de interdicción y el curador pueden demandar la anulación de los actos patrimoniales practicados en contravención del Artículo 591.

(39) Agradezco a Alejandro Calzetta por hacerme algunas precisiones en lo referente a este tema durante el desarrollo de mi investigación.

(40) Cabe señalar que A\&B (1987, p. 198-199) precisan que el sistema penal es relativamente cerrado, pero no porque este pudiese contemplar la existencia de lagunas normativas, sino porque dicho sistema se refiere únicamente al universo de soluciones penales y no al universo de soluciones que contempla la totalidad del sistema normativo. Aún así, consideran que, como los sistemas jurídicos son hipotéticos (y no categóricos), ningún sistema jurídico puede estar cerrado en sentido absoluto.

(41) Una laguna axiológica designa una situación en la que si bien existe una solución -a diferencia de lo que sucede cuando hablamos de una laguna normativa-, la solución existente es axiológicamente inadecuada porque el legislador no tuvo en cuenta una distinción o propiedad que debió considerar como relevante, pero que de haberla considerado hubiera dado una solución diferente al caso (A\&B, 1987, p. 159).

(42) Agradezco a Alejandro Calzetta por hacerme algunas precisiones en lo referente a este tema durante el desarrollo de mi investigación. 
norma de clausura que dé como resultado la permisión de la conducta no prohibida. $Y$ es que de la ausencia de regulación no es posible derivar ninguna obligación que sí podría darse con la regulación permisiva.

Para autores como Juan Ruiz Manero y Juan Carlos Bayón, la objeción señalada a la tesis de la equivalencia pragmática resultaría de no saber distinguir con claridad entre "permisos protegidos" y "permisos no protegidos"(43), pues si bien no existiría equivalencia pragmática entre la ausencia de prohibición y el permiso protegido, sí la habría entre la no prohibición y el permiso no protegido, o sea el permiso débil: "(...) si la tesis de la equivalencia pragmática mantuviese que la ausencia de regulación es equivalente a la existencia de un permiso protegido, entonces la objeción en su contra (...) sería certera: pero no lo es, porque lo que mantiene la tesis en cuestión no es eso, sino que la ausencia de regulación da lugar a una situación de permiso no protegido" (Bayón, 2009, p. 68).

Sin embargo, para Bulygin (2010, p. 295) el permiso no protegido no es algo distinto de la mera ausencia de una prohibición y, por tanto, contrariamente a lo sostenido por Bayón, se trata de un permiso vacío y carente de consecuencias normativas: "( ) si se toma en serio la afirmación de que el permiso no protegido implica ciertas consecuencias normativas resulta que todo caso para el cual por hipótesis no hay consecuencias normativas en el sistema (caso no prohibido), en realidad tiene consecuencias normativas en el sistema (por ser un caso de permiso no protegido)".

Quizás el tema se pueda resolver mejor si tomamos en cuenta cada uno de los elementos que en la presente investigación hemos ido atribuyendo al concepto de permisión, es decir: (i) se trata de una conducta con propiedades relevantes (para distinguirla de las conductas indiferentes), (ii) la acción a que se refiere el permiso es una facultad que tiene el sujeto, (iii) la realización de la acción no implica la violación de ninguna norma del sistema, y (iv) existe la obligación de los demás de facilitar o abstenerse de impedir la acción a que se refiere el permiso.

Para aquellos autores que sostienen la importancia de distinguir entre permisos protegidos y no protegidos, estos últimos estarían caracterizados únicamente por (ii) y (iii). Asimismo, aunque parezca una obviedad, es necesario agregar al concepto de permiso no protegido el elemento (i), es decir, que nos referimos a conductas con propiedades relevantes. En cambio, los permisos protegidos se caracterizarían además por (iv), es decir, se trata de actos con propiedades relevantes que se presentan como una facultad del sujeto, cuya realización no implica la violación de ninguna norma del sistema, y que van acompañados de una norma de cierre que prohíbe impedir la realización de toda conducta que el derecho no prohíbe (como se da en materia penal o administrativa), o de una norma que prohíbe la interferencia u obliga a la facilitación de dichos actos.

En ese sentido, bajo la distinción ente permisos protegidos y no protegidos diríamos que la regulación permisiva es un permiso protegido, en el sentido que nos permite apreciar con claridad la diferencia que existe entre afirmar que los sujetos tienen una libertad originaria y otorgar una libertad normativa a través de un acto de autoridad: si bien un permiso otorga la libertad de elegir, la norma permisiva además garantiza esa libertad. Esto guarda relación con lo señalado por Francesca Poggi (2004, p. 22-26), cuando se refiere a la función de las normas permisivas de hacer libres a los destinatarios de optar entre alternativas de comportamiento opuestas. Esta relación entre "permitir" y "querer que los destinatarios sean libres de elegir", según Poggi, no deriva de una implicación lógica, sino de una presuposición interpretativa que se traduce en un deseo de no interferir con el comportamiento permitido, lo que también es interpretado como una "promesa de no interferencia" o una "prohibición de interferencia". Por ello, cuando se busca responder qué se entiende por "dar la libertad de elegir", las alternativas brindadas por esta autora se refieren a la limitación de prohibiciones (preexistentes, sucesivas o contemporáneas).

Sin embargo, de lo anterior no se debe deducir que la ausencia de regulación es equivalente al permiso no protegido, y esto es así porque, tal como he concluido en el primer capítulo, en la esfera de las conductas no prohibidas (o no reguladas) se podrían presentar las siguientes situaciones: (i) que la conducta no prohibida se trate de una indiferencia normativa (casos en los que el derecho no regula ni pretende regular), (ii) que la conducta no prohibida tenga propiedades relevantes, pero no sea posible

(43) De acuerdo con Bayón (2009, p. 69), a estas mismas nociones se refiere Robert Alexy con los términos "libertades protegidas" y "libertades no protegidas". Asimismo, precisa que las libertades no protegidas no implican el derecho a no ser obstaculizado en el goce de estas libertades, y solo cuando se añade dicho derecho, la libertad no protegida se convierte en una libertad protegida. 
concretizarla sin regulación (casos de laguna normativa), o (iii) que la conducta no prohibida tenga propiedades relevantes y se encuentre disponible para el sujeto aún sin regulación (supuesto que hemos considerado como el único caso equivalente con la permisión).

Conforme a lo señalado, estarían dentro del concepto de permiso no protegido solamente los supuestos (ii) y (iii). La aplicación de la noción de permiso no protegido en el supuesto (ii) ayudaría a confirmar la existencia de lagunas normativas en los sistemas, y en la necesidad de que este tipo de conductas sean reguladas, pues en estos casos claramente no existe equivalencia pragmática entre la ausencia de regulación y la permisión. En cambio, la aplicación de la noción de permiso no protegido en el supuesto (iii) nos regresaría a nuestra postura inicial, es decir, que solo existiría equivalencia pragmática entre la no regulación y el permiso (no protegido) cuando este se traduce en una conducta no prohibida con propiedades relevantes que se encuentra disponible para el sujeto, aún sin regulación.

Como vemos, lejos de servir a los propósitos de quienes sostienen la tesis de la equivalencia pragmática, la distinción entre permisos protegidos y no protegidos termina apoyando nuestra tesis, es decir, que la norma permisiva agrega algo al concepto de permisión que no es posible encontrar en la mera ausencia de regulación, lo que hace que estas no sean equivalentes, y este elemento es la obligación de los demás de facilitar (o la prohibición de interferir en) la acción a que se refiere el permiso. Evaluemos algunos ejemplos prácticos.

Imaginemos que la autoridad decide no añadir una norma permisiva al sistema respecto de cierta conducta, bajo la idea de que ella no agregaría nada nuevo a la realidad, pues dicha norma al final cumpliría la misma función que si la conducta no estuviese prohibida (permiso débil). Dicha autoridad además ha sido asesorada por uno de los autores que sostiene la tesis de la equivalencia pragmática, para quien el derecho solo excluye la facultad de realizar una acción por un sujeto, si califica dicha acción como obligatoria o como prohibida, lo cual no ocurre si el derecho permite la realización y la omisión de dicha conducta o si se limita a no prohibirla: "Esta equivalencia pragmática para el sujeto de la acción entre el permiso positivo y la no prohibición es lo que hace que, en la mayor parte de los contextos, el dictado de disposiciones permisivas carezca de sentido" (Ruiz Manero, 2010, p. 300)(44).

Sin embargo, la simpleza de los ejemplos que parte de la doctrina ha venido empleando para mostrar dicha equivalencia, no permite evidenciar la relevancia práctica de las normas permisivas, por ejemplo, en el ámbito de los derechos. Podríamos probar evaluando otros casos en los que se aprecie mejor la necesidad de que ciertas conductas o estados de cosas estén regulados permisivamente.

Imaginemos que en el Perú existe una norma que permite a los estudiantes de escuelas públicas llevar el curso de religión católica, también correspondería decir que existe una norma que permite a estos estudiantes no llevar el curso de religión católica; este último supuesto valdría principalmente para aquellos estudiantes que profesan otra religión o no profesan ninguna. Por lo que podríamos decir que el sistema normativo peruano es completo y coherente en lo que se refiere a la facultad de llevar o no llevar el curso de religión católica en la educación pública. ¿Valdría lo mismo si dijésemos que no está regulado (o no está prohibido) que los estudiantes de escuelas públicas en el Perú lleven el curso de religión católica?

Otro ejemplo que podría complejizar aún más la necesidad de contar en sistemas jurídicos constitucionales con normas permisivas, es el caso de la maternidad subrogada o el también llamado "vientre de alquiler". Veremos que en muchos Estados no está prohibido que una mujer se embarace y dé a luz un niño para entregárselo a otra persona que no puede tener naturalmente

(44) El profesor Ruiz Manero (2010, p. 300-302) expone dos ejemplos para demostrar que su postura es cierta: El ejemplo 1 está referido a la acción de ingerir zumo de naranja en el desayuno como una facultad que se puede ejercer porque no hay ninguna regla que lo prohíba, entonces dice: ¿cambiarían las cosas si una autoridad normativa emitiera una disposición que permitiese la ingesta como la no ingesta de zumo de naranja en el desayuno? El ejemplo 2 está referido al permiso de sentarse en los bancos que están distribuidos a lo largo del campus de la Universidad de Alicante, facultad de la que Ruiz Manero disfruta en su calidad de profesor de dicha casa de estudios; este es un permiso débil porque no hay ninguna norma que se refiera a la acción de sentarse en los bancos, pero además es un permiso no protegido porque no va acompañado de una norma prohibitiva de acciones de interferencia, es decir, nadie está obligado a levantarse para que el profesor Ruiz Manero pueda sentarse; pero si el Consejo de Gobierno de la Universidad dictara una disposición que permitiera que todos los que se encuentren en el campus puedan sentarse en los bancos que hay en él, ¿cambiaría en algo las cosas de cómo eran antes del dictado de dicha disposición? En ambos ejemplos la respuesta de Ruiz Manero es negativa. 
hijos; no obstante, pocos podrían decir que debido a esa falta de prohibición expresa dicha figura está permitida, pues el funcionamiento práctico de nuestros sistemas jurídicos demostraría lo contrario(45).

La norma permisiva como tal es un permiso protegido, pues introduce ciertas garantías para que el sujeto pueda ejercer la "libertad de elegir" que le es otorgada mediante un acto de autoridad. En cambio, de la simple ausencia de regulación no se podrían inferir estas garantías, como el deber de la autoridad de adoptar aquellas acciones que faciliten la realización de la conducta permitida. Conforme a los ejemplos señalados, esto no solo significaría la prohibición de acciones que impidan que los sujetos puedan ejercer en la práctica la acción permitida, sino también la imposición de una serie de deberes a cargo del Estado para establecer un estado de cosas que garantice que estos sujetos puedan concretizar dicha facultad ${ }^{(46)}$.

Por lo tanto, es posible mostrar que las normas permisivas son relevantes en los sistemas normativos, principalmente en el marco de los Estados constitucionales, porque introducen algo que no se da en la mera ausencia de regulación, a fin de garantizar la libertad de elegir que es otorgada al sujeto. Esto no solo se restringiría a la limitación de prohibiciones, sino también a la introducción de obligaciones dirigidas a la autoridad.

\subsection{La limitación de competencias normativas en sistemas jerárquicamente estructurados}

Una última diferencia a destacar respecto a los permisos fuertes y débiles, y que tiene que ver con la utilidad práctica del concepto de permisión en la dinámica de los sistemas jurídicos con pluralidad de autoridades y competencias normativas, es el hecho que los actos permitidos en sentido fuerte por una autoridad superior son distintos a aquellos actos que no están prohibidos (o que están permitidos en sentido débil), esto debido a que una autoridad inferior solo podría prohibir aquellos actos permitidos en sentido débil, mas no podría prohibir los permisos aprobados por la autoridad superior. De manera que, el dictado de una norma permisiva por una autoridad superior cumpliría la función normativa de limitar la competencia de las autoridades inferiores (A\&B, 2010, p. 287).

Lo anterior demostraría, como señalan A\&B (1991, p. 237), y Navarro (2011, p. 118), que el concepto de permisión es una herramienta teórica importante para la descripción de la dinámica del orden jurídico, pues juega un papel relevante en la limitación de competencias normativas en sistemas jerárquicamente estructurados, como suele ser en los estados constitucionales ${ }^{(47)}$. Esta función incluso es reconocida por algunos autores que plantean la tesis de la equivalencia pragmática.

Por ejemplo, Ruiz Manero (2010, p. 303 ; 2017, p. 3) señala que la existencia de una norma permisiva puede marcar una diferencia con la inexistencia de una norma en un contexto de jerarquía de autoridades, tal como se suele presentar en los sistemas jurídicos:

"Si una autoridad de grado superior permite prescriptivamente una cierta acción en un cierto caso genérico ello implica la prohibición a las autoridades subordinadas a ella de interferir, prohibiendo, impidiendo o sancionando dicha acción en dicho caso genérico o en casos menos genéricos o individuales comprendidos en aquél. De esta forma, el permiso fuerte dictado por una autoridad de grado superior implica que ese permiso resulta protegido frente al uso por parte de autoridades normativas de grado inferior de sus poderes normativos".

(45) En agosto de 2018 los medios de comunicación en el Perú advirtieron de la detención de una pareja chilena que pretendía salir del país con unos bebés mellizos, alegando que eran sus hijos, mostrando para ello las partidas de nacimiento y los documentos de identidad de los dos niños. Inicialmente, según la noticia, se les investigó por el delito de trata de menores, dado que se detectó que ellos habían ingresado al país en condición de turistas y sin niños. Al ser interrogados, la pareja indicó que en una conocida clínica de Lima contactaron a una mujer con quien suscribieron un acuerdo notarial para llevar a cabo la figura de "vientre subrogado", en tanto no podían tener hijos de forma natural. Luego de este acuerdo, la pareja le hizo una transferencia embrionaria a la mujer, producto de lo cual quedó embarazada, estando durante 8 meses en contacto con ella, asumiendo sus gastos médicos y de alimentación. Posteriormente, se confirmó mediante una prueba de ADN que la paternidad de los bebés mellizos correspondía a la pareja chilena.

(46) Es importante destacar que cuando se piensa en normas permisivas sin las cuales no sería posible que el sujeto ejerza la conducta "no prohibida", muchos ejemplos nos remiten a los derechos de carácter social, lo que demostraría que las normas constitucionales que prescriben derechos y que son mandatos de optimización hacia el Estado (obligaciones), suelen conllevar la aprobación de normas permisivas para los sujetos, las que -conforme a mi planteamiento- son permisos protegidos porque garantizan una libertad normativa de elegir.

(47) Para Francesca Poggi (2004, p. 14), una de las funciones de las normas permisivas que dan cuenta de su relevancia práctica es la limitación de la competencia normativa de los órganos subordinados en ordenamientos jerárquicamente estructurados, en los cuales rigen criterios materiales de invalidez o criterios jerárquicos de solución de antinomias, como el de lex superior. 
En ese sentido, la aprobación de un permiso fuerte en un contexto de autoridades jerarquizadas, impone a las autoridades inferiores el deber de buscar la compatibilidad entre sus disposiciones y las normas dictadas por sus superiores. Al respecto, Alejandro Calzetta y Alessio Sardo (2014, p. 57) expresan lo siguiente:

"La función principal de una norma permisiva es impedir la acción coactiva de los oficiales públicos de cierto sistema jurídico en un cierto dominio -esto ocurre tanto si actúan como autoridades legisladoras o como aplicadoras del derecho- y causa su falta de competencia para producir cualquier tipo de norma que sea incompatible con el patrón de comportamiento que está permitido. Por supuesto, este es el caso solo en una dirección arriba-abajo, y no abajo-arriba: la competencia del soberano (...) no está de ningún modo limitada por una permisión que haya sido emitida desde un nivel inferior. El soberano puede cambiar su parecer y derogar la permisión expresa".

Sin embargo, los filósofos polacos O\&W se niegan a reconocer que las normas permisivas cumplan dicha función, dándole una mirada distinta al clásico ejemplo (imaginario) del cacique Toro Sentado planteado por Echave, Urquijo y Guibourg (1986, p. 155), el cual utilizan autores como A\&B para demostrar la relevancia práctica de las normas permisivas en la dinámica de los ordenamientos jurídicos y su diferencia con las conductas no prohibidas o los permisos débiles. Dicho ejemplo señala lo siguiente:

El cacique Toro Sentado dictó una norma permisiva para los miembros de su tribu, facultándolos a cazar los martes y los jueves. Según él, esto no significaba una prohibición a cazar el resto de días de la semana, sino que sobre estos días simplemente no estaba regulando nada. Esto tampoco significaba una promesa de no prohibir en el futuro la caza los martes y los jueves, pues como cualquier gobernante podía cambiar de parecer. Ahora bien, para su tribu la introducción de esta norma permisiva parecería ser una cosa totalmente inútil, pues no iba a generar ningún cambio en sus conductas, es decir, las cosas seguirían igual.

De acuerdo a Echave, Urquijo y Guibourg (1986, p. 156), el desconcierto de los miembros de la tribu es, en realidad, el resultado de una expectativa fundada en la utilidad práctica de las normas: "Un sistema normativo implica la intención de regular, encauzar, definir límites. En otras palabras, ordenar lo no ordenado". Esto es lo que sucede con las normas permisivas, se asume su inutilidad en tanto no llegan a producir una variación en la expectativa del destinatario de la norma.

A\&B (1991, p. 236) señalan que el ejemplo del cacique Toro Sentado es interesante porque "muestra que las normas puramente permisivas carecen de interés práctico" en sistemas en los que existe una sola autoridad normativa, pero esto cambia cuando existen varias autoridades jerárquicamente ordenadas. En efecto, imaginemos, dicen estos autores, que un día Toro Sentado decidió nombrar a un ministro a quien autorizó dictar nuevas normas y derogarlas, pero carece de competencias para derogar las normas dictadas por el cacique. De manera que el permiso de Toro Sentado puede ser interpretado como un rechazo anticipado de una posible prohibición por parte del ministro de cazar los martes y los jueves, y una norma de esta naturaleza no sería válida en tanto el ministro carecería de competencia para dictarla.

Conforme a lo planteado por A\&B, queda demostrado que existe una diferencia entre aquellos actos permitidos en sentido fuerte por el cacique Toro Sentado y aquellos actos que no están prohibidos o están permitidos en sentido débil, pues estos últimos sí podrían ser materia de prohibición por el ministro.

Al respecto, $\mathrm{O} \& \mathrm{~W}(1986$, p. 86) dirán que no se altera en nada la disposición de Toro Sentado si este le dice a su ministro que regule como él desee, pero que trate la caza de los martes y los jueves como actos indiferentes ${ }^{(48)}$; con lo cual se podría decir que la primera norma de Toro Sentado fue un error verbal, y que sus disposiciones siguientes pueden ser descritas por medio de obligaciones (prohibiciones) e indiferencia. Por tanto, estos autores dirán que el ejemplo del cacique Toro Sentado no fuerza a uno a reconocer la importancia de los permisos fuertes y las normas permisivas.

Lo que plantean O\&W es que la supuesta prohibición dirigida a la autoridad inferior de derogar los permisos fuertes de la autoridad superior, no es otra cosa que un mandato a tratar el permiso como un acto de indiferencia. Encuentro dos observaciones a dicha lectura:

Primero, los permisos fuertes de la autoridad superior son permisos protegidos, esto quiere decir que son actos con propiedades relevantes que se presentan como una facultad del sujeto, cuya realización no implica la violación de ninguna norma del sistema, y que van acompañados de una

(48) "Do regulate as you will, but treat the hunting on Tuesday and Friday as indifferent acts". (O\&W, 1986, p. 86) Atendiendo al ejemplo original, deberá entenderse que el texto quiso hacer referencia a los días martes y jueves. 
norma que prohíbe la interferencia u obliga a la facilitación de los actos permitidos; todos estos elementos hacen difícil asimilar el permiso fuerte con los actos indiferentes, que por definición son casos cuyas propiedades son jurídicamente irrelevantes, y por ende, casos que el derecho no regula ni pretende regular.

Segundo, podría existir equivalencia entre los actos indiferentes y los permisos débiles de la autoridad superior, o aquellas conductas no prohibidas por él; sin embargo, esto es algo contingente, pues algunas de estas conductas no reguladas podrían consistir en lagunas normativas. Por ejemplo, si el ministro verificase que no existe reservado un día de la semana para que los miembros de la tribu lleven a cabo labores de culto a su dios, y que por ello dichas actividades se llevan de forma indiscriminada pues durante la semana se privilegia la realización de actividades de caza, dicha autoridad habría establecido una propiedad relevante que configuraría un caso que necesita una regulación, es decir, habría identificado una laguna normativa, y esto no podría asimilarse con un acto de indiferencia. En ese sentido, el ministro estaría facultado para dictar una norma que prohíba expresamente la caza cualquier día de la semana, menos los martes y los jueves, a fin que los miembros de la tribu puedan realizar labores de culto a su dios.

\section{Conclusiones}

\section{A. Sistema normativo y razonamiento jurídico:}

Propiedades relevantes, conductas reguladas y no reguladas:

- Las propiedades relevantes son aquellas que elige el legislador y designa como tal para configurar una conducta. El proceso de determinación de las propiedades relevantes, es decir, las propiedades que merecen ser tenidas en cuenta, es un problema subjetivo, valorativo o axiológico que atañe exclusivamente al legislador.

- La existencia de conductas reguladas no determina la relevancia o irrelevancia de las propiedades de las conductas no reguladas, en tanto muchas de estas no han sido sometidas a la valoración del legislador (o no pudieron ser consideradas ex ante o aún no se habían configurado).

- El derecho suele observarse en un sentido abstracto o conceptual como un conjunto de normas con carácter prescriptivo coherentemente relacionadas, lo que hace que se le considere un sistema; pero, el sistema normativo no representa en su totalidad el derecho, sino el conjunto de enunciados que conectan casos con soluciones.

- Las normas jurídicas son entidades o expresiones lingüísticas que correlacionan casos con soluciones, sin que por ello se afecte el carácter ontológico de las mismas. La producción de estas normas consiste en un acto pragmático, cuyo resultado tiene un lado sintáctico y otro semántico.

Indiferencia y laguna normativa

- La indiferencia guarda relación con las conductas no reguladas y con la esfera extranormativa, pero no en un sentido de equivalencia. El concepto de indiferencia presupone la irrelevancia jurídica de las propiedades de las conductas indiferentes, mas no de todas las conductas no reguladas.

- Las lagunas son casos no regulados, pero no todos los casos no regulados son lagunas; no se trata de aquellos casos en los que el derecho no regula ni pretende regular (actos indiferentes), sino de aquellos casos para los que el derecho no contempla solución normativa alguna, a pesar de que debería debido a su relevancia prescriptiva.

\section{Pertenencia al sistema normativo}

- No cabe mayor discusión sobre la pertenencia de las normas al sistema normativo, en tanto estas hayan sido aprobadas cumpliendo con las normas para la producción jurídica, las cuales establecen procedimientos mínimos y necesarios, tales como la aprobación por el órgano competente y la publicidad según mandato constitucional.

- El hecho que una conducta no regulada tenga ciertas propiedades relevantes en sentido prescriptivo, no determina su pertenencia al sistema normativo; dicha falta de pertenencia tampoco cambiaría por el hecho de que tal conducta pueda resolverse con la sola aplicación de mecanismos de interpretación.

- Solo las conductas reguladas pertenecen al sistema normativo; en cambio, no pertenecen al sistema aquellas conductas no reguladas con propiedades relevantes que no tienen una solución por parte del sistema (lagunas normativas), las conductas no reguladas que a través de la aplicación de prácticas interpretativas podrían tener una solución (permisos débiles), ni las conductas no reguladas cuyas propiedades son jurídicamente irrelevantes (indiferencia normativa). 
B. La supuesta completitud y coherencia de los sistemas normativos:

\section{El imperativismo y la permisión}

- En términos generales, la teoría imperativista de las normas sostiene que no existen normas permisivas, pues permitir no constituye (por definición) un uso normativo del lenguaje, por ende, todas las normas de conducta se reducen a obligaciones o prohibiciones.

- Desde un imperativismo fuerte o radical se sostiene que un sistema normativo es un conjunto de consecuencias lógicas de un determinado conjunto finito de obligaciones básicas, cuyos enunciados expresan una decisión de una autoridad normativa de que algunas acciones se consideran obligatorias, por lo que no hay espacio para los conceptos de permiso débil (negativo) o permiso fuerte (positivo).

- Negar la importancia de los permisos fuertes y la existencia de una esfera extranormativa, como lo hace el imperativismo fuerte o radical, representa una dificultad a la hora de establecer algunas de las funciones que cumplen las normas permisivas y que hacen que sean relevantes para los sistemas normativos.

El uso prescriptivo y descriptivo de los términos deónticos, y los conceptos de permiso

- La práctica de los sistemas jurídicos muestra que no siempre es posible equiparar una conducta "regulada" como no prohibida (o permitida) con una conducta no prohibida, y esto pasa por saber distinguir entre normas y proposiciones normativas.

- Los términos deónticos "permitido" y "prohibido" tienen significados diferentes cuando se usan en los planos prescriptivo y descriptivo. En ese sentido, existen tres conceptos de permisión: un concepto de permisión prescriptiva y dos conceptos de permisión descriptiva (permiso fuerte y permiso débil).

- El permiso fuerte no es un concepto prescriptivo o un carácter normativo, solo lo es la norma permisiva. En ese sentido, solo la norma permisiva podría ser sometida a derogación, lo que no podría suceder con los otros dos conceptos de permisión (el permiso fuerte y débil) por tratarse de proposiciones normativas.

La tesis refleja, la tesis de la equivalencia pragmática, y el ideal de completitud y coherencia de los sistemas normativos

- La tesis refleja plantea que no existen normas permisivas porque todas las normas son imperativas (prohíben $u$ obligan). De esta tesis se deriva la idea de la interdefinibilidad de los términos "prohibición" y "permisión" o la regla permisiva de clausura: "lo que no está prohibido está permitido".
- Los casos de indiferencia o laguna normativa muestran que no siempre existe equivalencia pragmática entre la conducta no regulada y el permiso. Por ello, la tesis de la equivalencia pragmática entre la no prohibición y la regulación jurídica no se condice con la práctica de los sistemas jurídicos y con la necesidad de garantizar el ejercicio de las conductas permitidas.

- Señalar que los sistemas normativos son completos y coherentes nos llevaría a tener que sostener implícitamente que la función legisladora del Estado es una cuestión acabada, pues dejaría de tener sentido la introducción de nuevas normas en tanto las interpretaciones jurídicas podrían suplir perfectamente la regulación de las conductas.

- Si bien los procesos de identificación o explicitación de las normas que se llevan a cabo a través de la aplicación de técnicas de interpretación son necesarios para completar la labor que realizan los tribunales, estos no pueden equipararse con la regulación normativa.

Complementariedad de las concepciones semántica y pragmática de las normas, e interpretación de la tesis refleja a la luz de la distinción entre permisos fuertes y débiles

- La concepción semántica de las normas y la concepción pragmática de las normas no son excluyentes, sino complementarias: a) las normas son los significados de enunciados usados para prescribir; $y, b)$ las normas no pueden existir sin enunciados que las expresen o actos de lenguaje.

- Es posible demostrar que existen conductas o estados de cosas con propiedades relevantes que no están regulados por un sistema normativo (lagunas normativas), haciendo que este sea incompleto; o que existen normas contradictorias en un mismo sistema (conflictos normativos), haciendo que este sea incoherente; pero esto no significa que se deba rechazar de plano la tesis de la interdefinibilidad de los términos deónticos "prohibido" y "permitido". 
- Si aceptamos que una norma es distinta a la formulación que la expresa y que su existencia depende de hechos empíricos, así como, que el uso prescriptivo y descriptivo de los términos deónticos "permitido" y "prohibido" tiene significados diferentes, entonces no es posible admitir el reduccionismo del concepto de permisión o solo aceptar este reduccionismo para ciertos casos.

C. La importancia de las normas permisivas, en el marco de los estados constitucionales

\section{La función de clausura de los sistemas normativos}

- Las normas permisivas son autónomas porque cumplen la función normativa irremplazable de autorizar conductas y clausurar el sistema normativo sin introducir incoherencias, algo que no puede lograrse a través de otras normas. Este planteamiento es interesante porque no busca responder si los sistemas normativos son cerrados o completos, sino cómo podemos lograr que lo sean.

- La ausencia de regla en el ámbito sancionador implica que la conducta en cuestión resulte definitiva o concluyentemente permitida (regla de clausura permisiva), lo cual marca una diferencia fundamental con otros sectores del derecho, como el privado. De esto se deriva que el derecho penal, como sistema de prohibiciones, no contiene lagunas.

- Si bien es posible que una conducta esté penalmente permitida pero prohibida en otro ámbito del derecho (por ejemplo, el civil), ello no significa que la conducta no tipificada no esté permitida penalmente; no obstante, dicha situación puede acarrear desde el punto de vista lógico contradicciones o antinomias en los sistemas jurídicos.

- Las conductas no tipificadas penalmente, y que para el intérprete deberían estarlo (ya sea porque existen razones de naturaleza social para ello o porque otros sistemas jurídicos sí las regulan), no son lagunas normativas, sino que podrían considerarse lagunas axiológicas.

\section{La función de dar la libertad normativa de elegir}

- La distinción entre permisos protegidos y no protegidos permite demostrar lo contrario a la tesis de la equivalencia pragmática, al evidenciar que la norma permisiva agrega algo al concepto de permisión que no es posible encontrar en la mera ausencia de regulación, a fin de garantizar la libertad de elegir del sujeto. Esto sería la prohibición (hacia los demás) de no interferir en la acción a que se refiere el permiso y la obligación (de la autoridad) de facilitar la conducta permitida.

- La norma permisiva es un permiso protegido que en el caso de los derechos introduce el deber de la autoridad de adoptar acciones que faciliten la realización de la conducta permitida, por lo que este tipo de regulación no solo se restringe a la limitación de prohibiciones sino también a la introducción de obligaciones.
La función de limitar las competencias normativas en sistemas jerárquicamente estructurados

- Los actos permitidos en sentido fuerte por una autoridad superior son distintos a aquellos actos que no están prohibidos por este, en el sentido que una autoridad inferior solo podría prohibir aquellos actos permitidos en sentido débil, más no podría prohibir los permisos aprobados por la autoridad superior. Por ello, el dictado de una norma permisiva por una autoridad superior cumple la función normativa de limitar las competencias de las autoridades inferiores.

- Los permisos fuertes de la autoridad superior son permisos protegidos, lo cual hace difícil que puedan asimilarse con los actos indiferentes, que por definición son casos cuyas propiedades son jurídicamente irrelevantes. Asimismo, podría existir equivalencia entre los actos indiferentes y los permisos débiles de la autoridad superior; sin embargo, esto es algo contingente, pues dichas conductas no reguladas podrían contener lagunas normativas.

\section{Referencias bibliográficas}

Alchourron, C. \& Bulygin, E. (1981). La concepción expresiva de las normas. En R. Hilpinen (edit.), New Essays in Deontic Logic (p. 121-154). Dordrecht: Reidel.

(1984). Permisos y normas permisivas. En W. Krawietz et al (edit.), Theorie der Normen, (p. 215-238). Berlín: Duncker \& Humblot Gmbh.

(1985). Libertad y autoridad normativa. Boletín de la Asociación Argentina de Filosofía del Derecho, 3(26), p. 239-247.

(1987). Introducción a la metodología de las ciencias jurídicas y sociales. Buenos Aires: Editorial Astrea Edición digital de la Biblioteca Virtual Miguel de Cervantes, Alicante.

(1991). Análisis lógico y derecho. Madrid: Centro de Estudios Constitucionales.

Bayón, J. (2009). Sobre el principio de prohibición y las condiciones de verdad de las proposiciones normativas. En E. Bulygin, M. Atienza \& J. Bayón (edit.), Problemas lógicos en la teoría y práctica del Derecho (p. 27-73). Madrid: Fundación Coloquio Jurídico Europeo. 
Bulygin, E. (2005). Creación y aplicación del derecho. En F. Atria, E. Buligyn, J. Moreso, P. Navarro, J. Rodríguez \& J. Manero (edit.), Lagunas en el derecho. Una controversia sobre el derecho y la función judicial (p. 29-44). Madrid-Barcelona: Marcial Pons.

(2009). La importancia de la distinción entre normas y proposiciones normativas. En E. Bulygin, M. Atienza \& J. Bayón (edit.), Problemas lógicos en la teoría y práctica del Derecho (p. 9-26). Madrid: Fundación Coloquio Jurídico Europeo.

. (2010). Sobre la equivalencia pragmática entre permiso y no prohibición. Doxa. Cuadernos de Filosofía del Derecho, 33, p. 283-296.

Calzetta, A. \& Sardo A. (2014). Una nueva visita a la concepción expresiva. Doxa. Cuadernos de Filosofía del Derecho, 37, p. 45-62.

Echave, D \& alt. (1986). Lógica, proposición y norma (2da ed.). Buenos Aires, Editorial Astrea.

Ferrer, J. y Rodríguez, J. (2011). Jerarquías normativas y dinámica de los sistemas jurídicos. Madrid: Marcial Pons.

Francisco, H. (2015). Sistema Estándar de Lógica Deóntica. Revista Versiones, 2 (7), p. 100-112.

Guastini, R. (1999). Antinomias y Lagunas, Jurídica. Anuario del Departamento de Derecho de la Universidad Iberoamericana, 29, p. 437-450.

(2001). Cinco observaciones sobre validez y derogación. Revista Discusiones. Derechos y justicia constitucional, 2, p. 59-63.

(2017). Dos concepciones de las normas. Revus. Journal for constitutional theory and philosophy of Law, p. 1-11.

Huerta, C. (2003). Conflictos normativos. UNAM Instituto de Investigaciones Jurídicas, Serie Doctrina Jurídica, 142, p. 7-45.

Iturralde, M. (1998). Consideración crítica del principio de permisión según el cual "lo no prohibido está permitido. Anuario de Filosofía del Derecho, 15 , p. $187-218$

Kelsen, H. (1998). Teoría Pura del Derecho (10ma ed.). México D.F.: Editorial Porrúa.

Kristan, A. (2014). En defensa de la concepción expresiva de las normas. Doxa. Cuadernos de Filosofía del Derecho, 37, p. 63-82.

(2017). Derecho y otros enigmas (1ra ed.). España: Editorial Marcial Pons Ediciones Jurídicas y Sociales.
Navarro, P. (2007). Eugenio Bulygin y la filosofía del derecho contemporánea. En J. Moreso \& M. Redondo (edit), Un diálogo con la teoría del derecho de Eugenio Bulygin, (p. 15-32). Madrid: Marcial Pons Ediciones Jurídicas y Sociales.

(2011). Normas permisivas y clausura de los sistemas normativos. Isonomía, 34, p. 109-140.

(2013). Lagunas, permisos y discreción. Análisis Filosófico, 23 (1), p. 103-123.

Opalek, K. \& Wolenski, J. (1973). On weak and strong permissions. Rechtstheorie, 4, p. 169-182.

1986). On weak and strong permissions one more. Rechtstheorie, 17, p. 83-88.

(1991). Normative Systems, Permission and Deontic Logic. Ratio Juris, 4(3), p. 334-348.

(2014). Ser, deber y lógica. Revus. Journal for constitutional theory and philosophy of Law, 23, p. 31-48.

Poggi, F. (2004). Sobre las normas permisivas. Revista Escuela de Derecho, 5(5), p. 11-32.

Redondo, M. (1990). Permisiones y actitudes normativas. Doxa. Cuadernos de Filosofía del Derecho, 7, p. 249-256.

(2006). Sobre la completitud de los sistemas jurídicos. Análisis Filosófico, 26(2), p. 294-324

Rodríguez, J. (2006). La tensión entre dos concepciones de los sistemas jurídicos. Estudio en homenaje a Carlos Eduardo Alchourrón. Análisis Filosófico, 26(2), p. 242-276.

Rojina, R. (1942). La conducta jurídicamente regulada. Teoría de la conducta jurídica. Escuela Nacional de Jurisprudencia, p. 27-70.

Ruiz, J. (2005). Algunas concepciones del derecho y sus lagunas. En F. Atria, E. Bulygin, J. Moreso, P. Navarro, J. Rodríguez \& J. Manero (edit.), Lagunas en el derecho: una controversia sobre el derecho y la función judicial (p. 103-126). Madrid: Marcial Pons.

(2010). Seguimos discutiendo sobre permisos y concepciones del Derecho. Doxa. Cuadernos de Filosofía del Derecho, 33 , p. 297-306.

(2015). Sistema jurídico: Lagunas y antinomias. En D. González (coord.), Conceptos básicos del derecho (p. 47-64). Madrid, Marcial Pons.

. (2017). Diez observaciones y un cuadro final sobre permisos y normas permisivas. Revus. Journal for constitutional theory and philosophy of Law, p. 1-10.

Von, G. (1963). Norm and Action: A logical enquiry, London: Routledge and Kegan Paul.

Wintgens, L. (2003). Legisprudencia como una Nueva Teoría de la Legislación. Doxa. Cuadernos de Filosofía del Derecho, 26, p. 261-287.

Wolenski, J. (2018). Enunciados deónticos, mundos posibles y normas. Revus. Journal for constitutional theory and philosophy of Law, p. 1-10. 